\title{
Immunosuppressive 9,10-Secosteroids from the Gorgonian Verrucella umbraculum Collected in the South China Sea
}

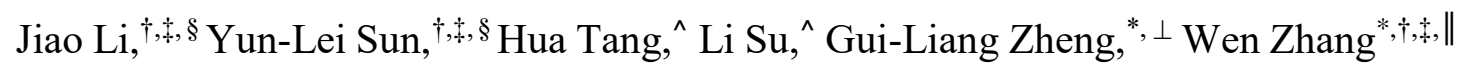

${ }^{\dagger}$ College of Pharmaceutical Science, Zhejiang Chinese Medical University, Gao-Ke

Rd., Hangzhou 311402, P. R. China

ॠSchool of Pharmacy, Second Military Medical University, 325 Guo-He Rd., Shanghai 200433, P. R. China

${ }^{\wedge}$ Institute of Translational Medicine, Shanghai University, 99 Shangda Rd., Shanghai 200444, P. R. China

${ }^{\perp}$ Department of Otorhinolaryngology, Head and Neck Surgery, Xinhua Hospital Affiliated to Shanghai Jiao Tong University School of Medicine, 1665 Kong-Jiang Rd., Shanghai 200092, P. R. China

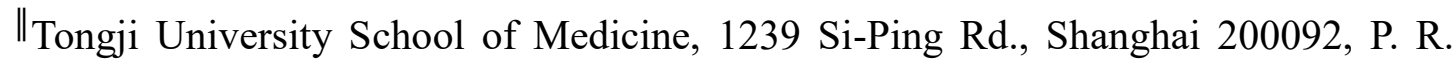
China

§These authors contributed equally to this work.

*Corresponding authors.

E-mail address: wenzhang1968@163.com (W.Z.); icing_blue@126.com (G.Z.) 


\section{Table of contents}

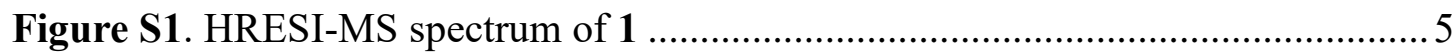

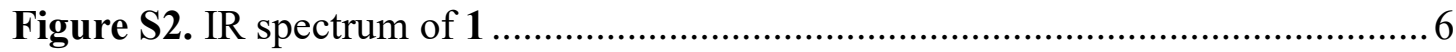

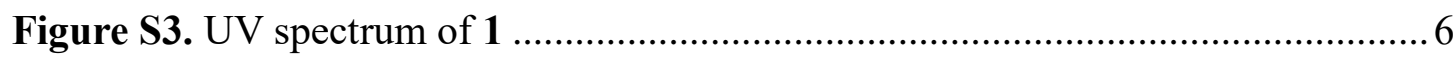

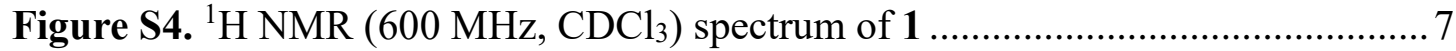

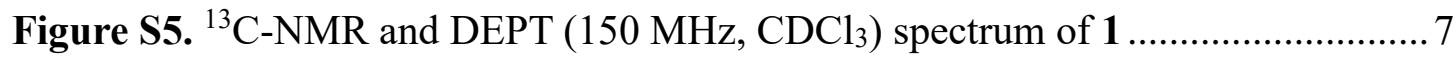

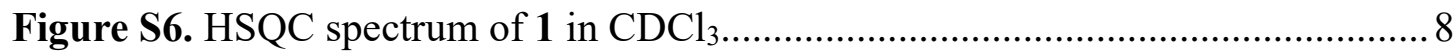

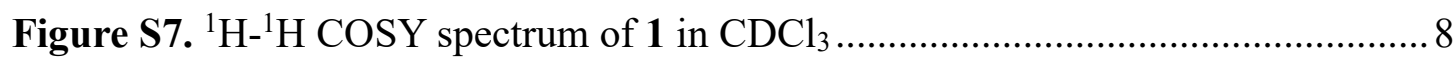

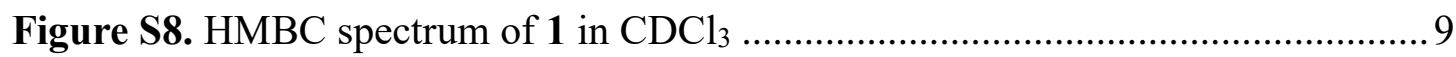

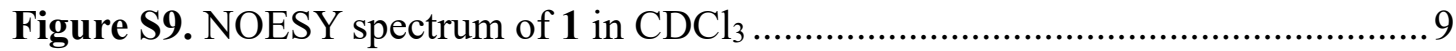

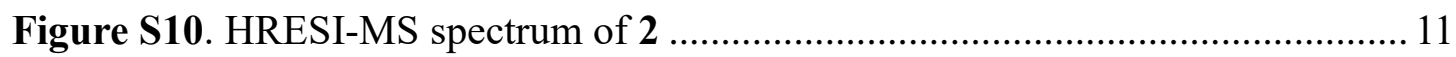

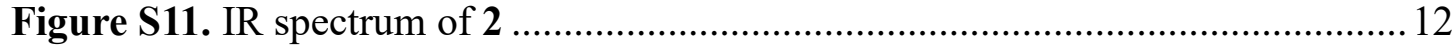

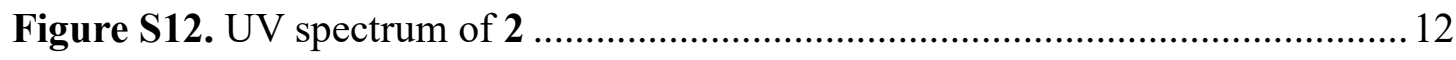

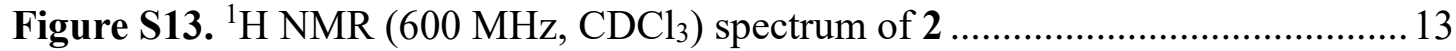

Figure S14. ${ }^{13} \mathrm{C}-\mathrm{NMR}$ and DEPT $\left(150 \mathrm{MHz}, \mathrm{CDCl}_{3}\right)$ spectrum of 2 .......................... 13

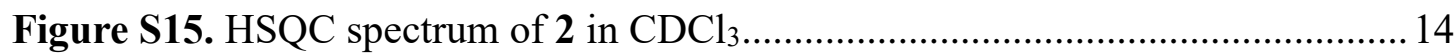

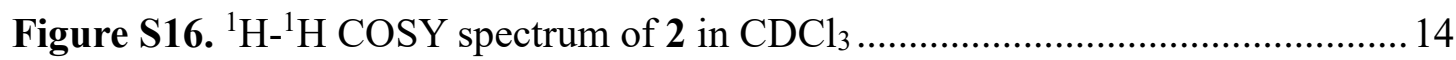

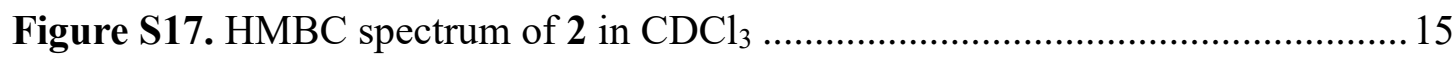

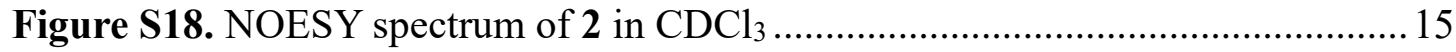

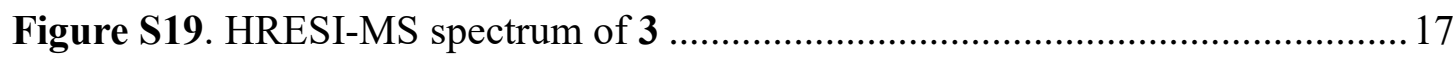

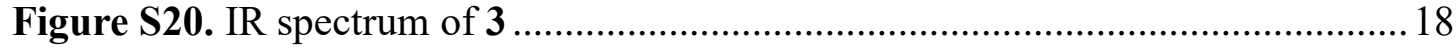

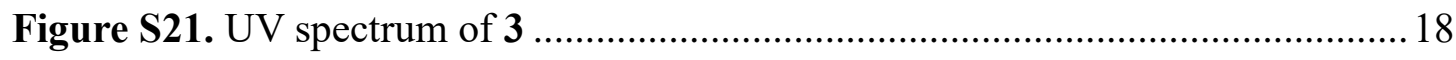

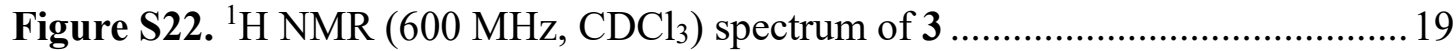

Figure S23. ${ }^{13} \mathrm{C}-\mathrm{NMR}$ and DEPT $\left(150 \mathrm{MHz}, \mathrm{CDCl}_{3}\right)$ spectrum of 3 ....................... 19

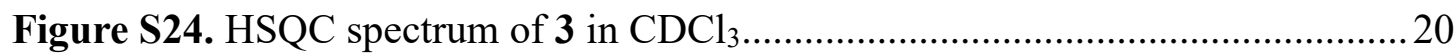

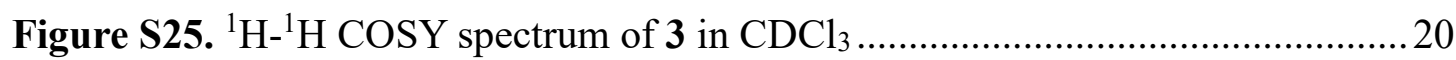

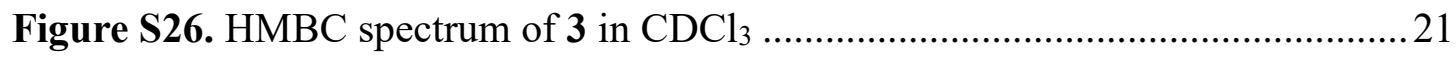

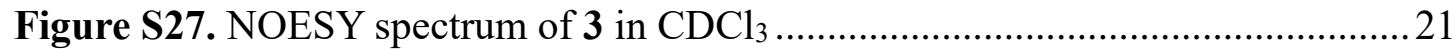

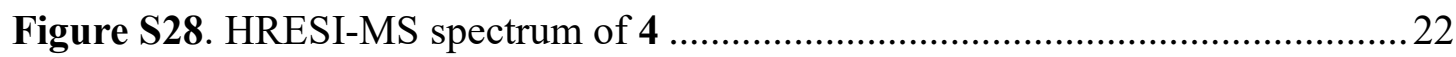




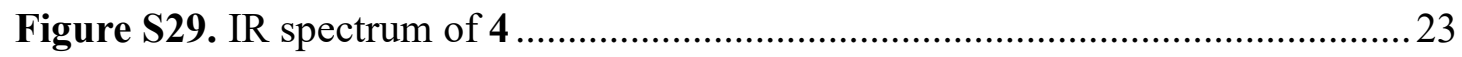

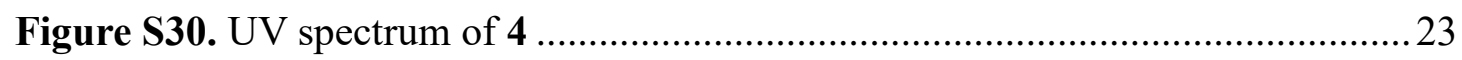

Figure S31. ${ }^{1} \mathrm{H}$ NMR $\left(600 \mathrm{MHz}, \mathrm{CDCl}_{3}\right)$ spectrum of 4 ........................................2

Figure S32. ${ }^{13} \mathrm{C}-\mathrm{NMR}$ and DEPT $\left(150 \mathrm{MHz}, \mathrm{CDCl}_{3}\right)$ spectrum of 4 .......................24

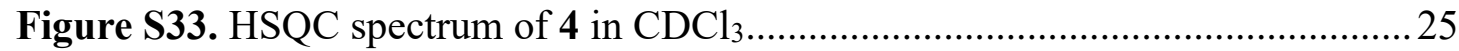

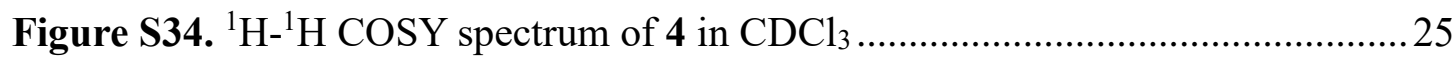

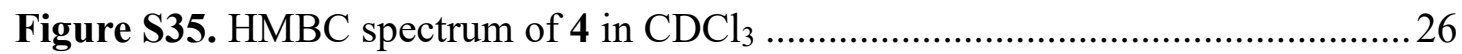

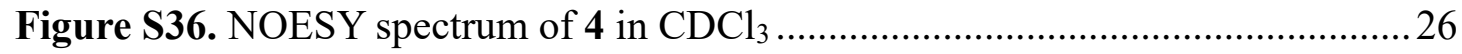

Figure S37. Cytotoxic assay of compounds 1-16 towards PBMC at the concentration

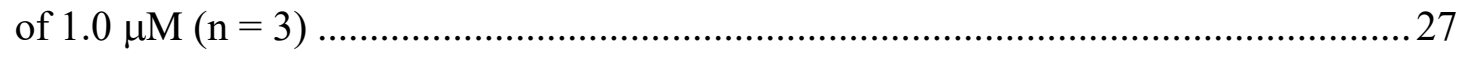




\section{定性分析报告}

$\begin{array}{llll}\text { 数据文件名称 } & \text { F53-NEG.d } & \text { 样品名称 } & \\ \text { 样品类型 } & \text { Sample } & \text { 位置 } & \text { P1-D4 } \\ \text { 仪器名称 } & \text { Instrument 1 } & \text { 用户名 } & \\ \text { 采集方法 } & \text { TEST-NEG.m } & \text { 采集时间 } & 3 / 12 / 2018 \text { 12:28:51 PM } \\ \text { IRM 校正状态 } & \text { Some Ions Missed } & \text { DA 方法 } & \text { Ij.m } \\ \text { 注释 } & & & \\ \text { Sample Group } & \text { Info. } & & \end{array}$

User Spectra

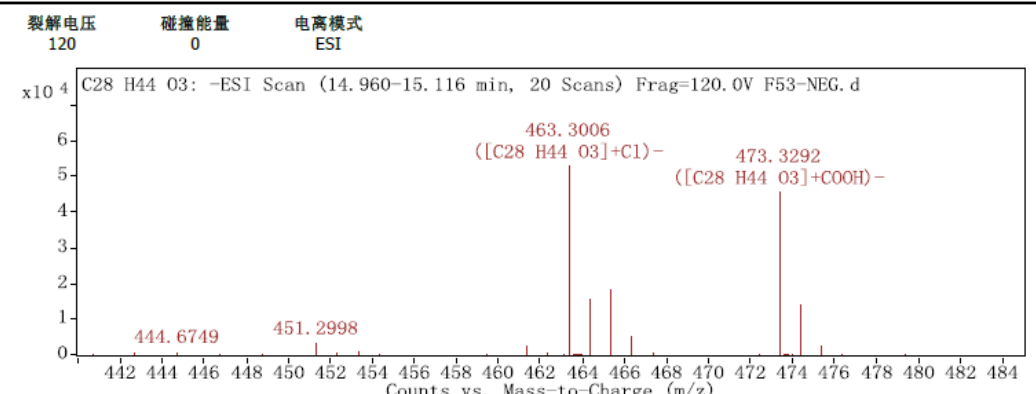
Counts vs. Mass-to-Charge (m/z)

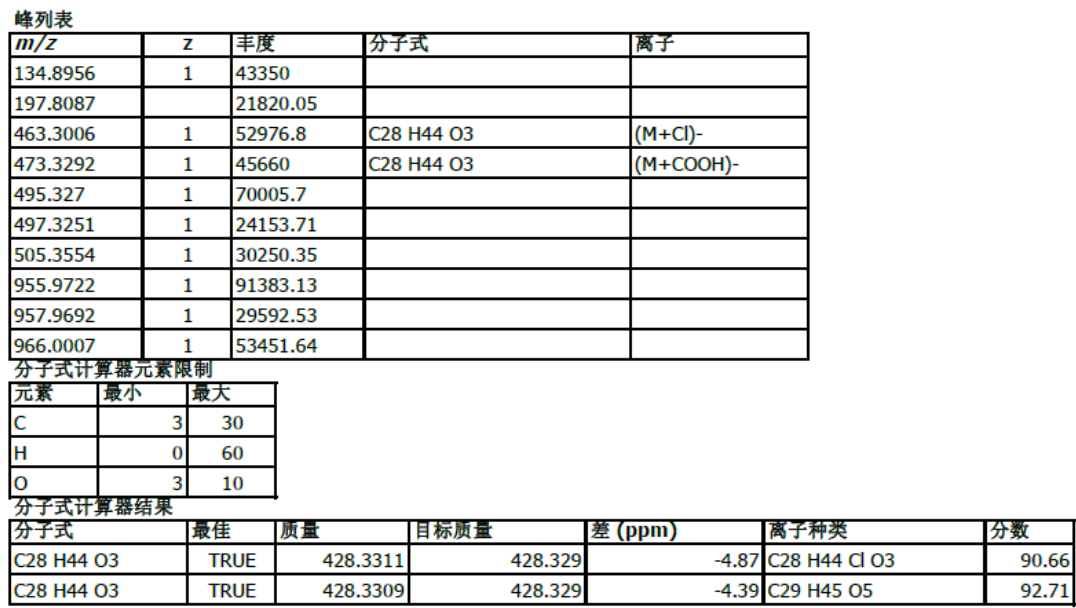

-- 报告结束 --- 
定性分析报告

\begin{tabular}{|c|c|c|}
\hline 数据文件名称 & F53-POS.d & 样品名称 \\
\hline 样品类型 & Sample & P1-D4 \\
\hline 仪器名称 & Instrument 1 & 用户名 \\
\hline 采集方法 & TEST-POS.m & 采集时间 2018/3/12 9:54:59 (UTC+08:00) \\
\hline $\begin{array}{l}\text { IRM 校正状态 } \\
\text { 注释 }\end{array}$ & 成功 & DA 方法 Default.m \\
\hline Sample Group & & Info. \\
\hline 采集时间 (当地) & $\begin{array}{l}\text { 2018/3/12 9:54:59 } \\
\text { (UTC+08:00) }\end{array}$ & \\
\hline
\end{tabular}

化合物

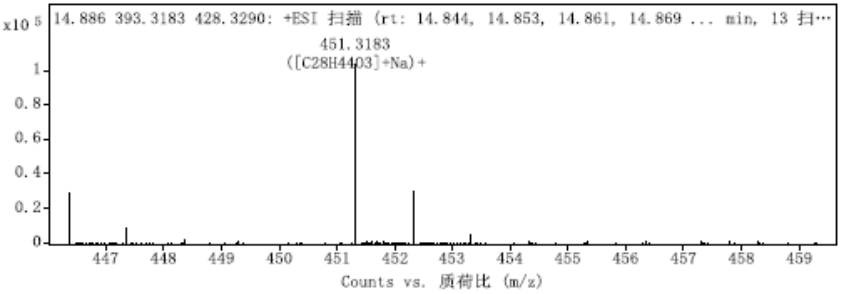

\begin{tabular}{|c|c|c|c|c|}
\hline$m / z$ & $z$ & 聿复 & 分子式 & T嘼子 \\
\hline 451.3183 & 1 & 102982.87 & $\mathrm{C} 28 \mathrm{H} 44 \mathrm{O} 3$ & $(\mathrm{M}+\mathrm{Na})+$ \\
\hline 452.3215 & 1 & 29695.57 & $\mathrm{C} 28 \mathrm{H} 44 \mathrm{O} 3$ & $(\mathrm{M}+\mathrm{Na})+$ \\
\hline 453.3243 & 1 & 5096.25 & $\mathrm{C} 28 \mathrm{H} 44 \mathrm{O} 3$ & $(\mathrm{M}+\mathrm{Na})+$ \\
\hline 454.3256 & 1 & 664.2 & $\mathrm{C} 28 \mathrm{H} 44 \mathrm{O} 3$ & $(\mathrm{M}+\mathrm{Na})+$ \\
\hline
\end{tabular}

报告结束 -

Figure S1. HRESI-MS spectrum of 1 

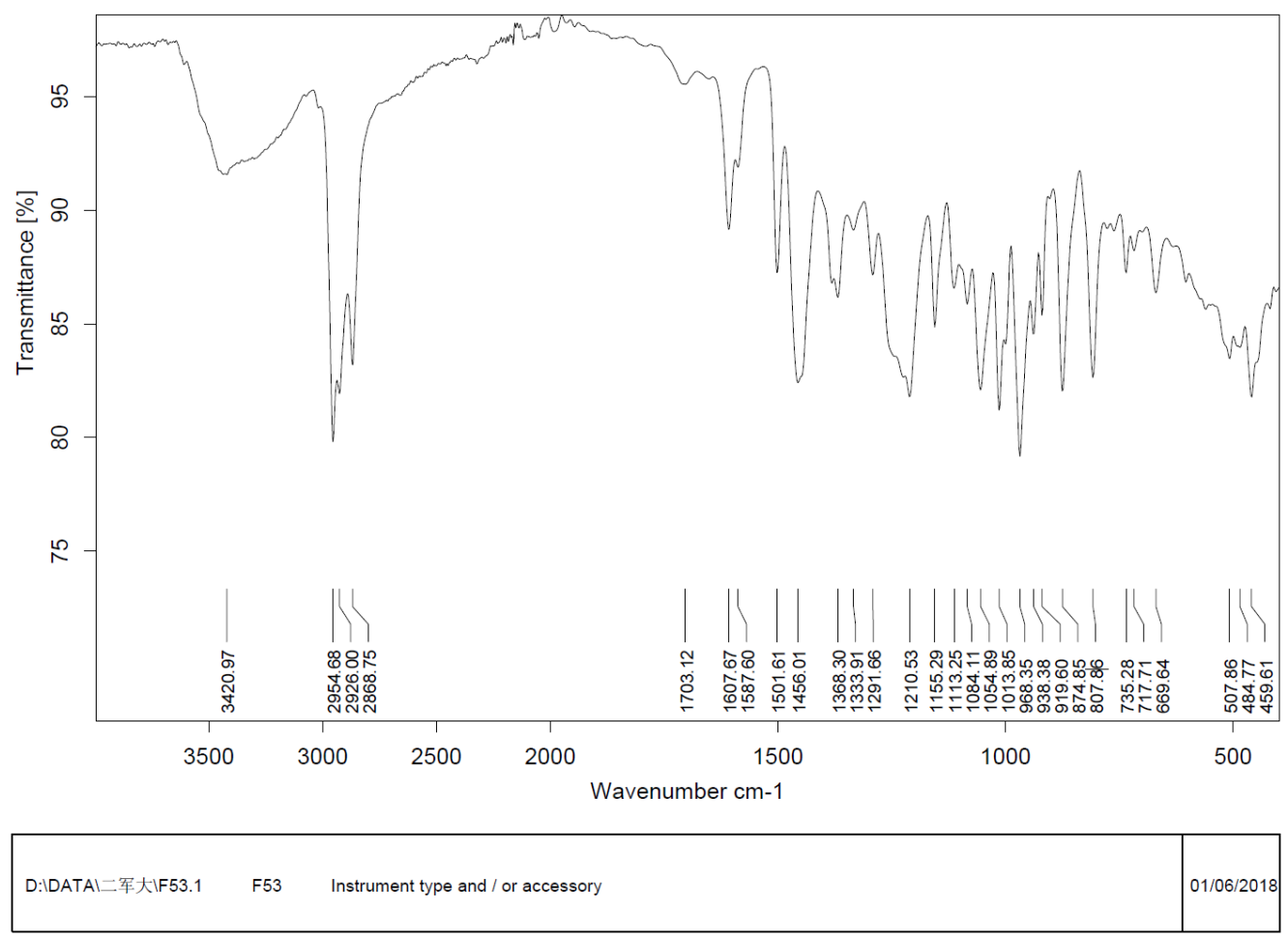

Page 1/1

Figure S2. IR spectrum of 1

State Key Laboratory of Organometallic Chemistry

Shanghai Institute of Organic Chemistry

Chinese Academy of Sciences

光谱测定报告

打印日期时间： 2018/03/21 15:16:21

文件名:

f53 - RawData

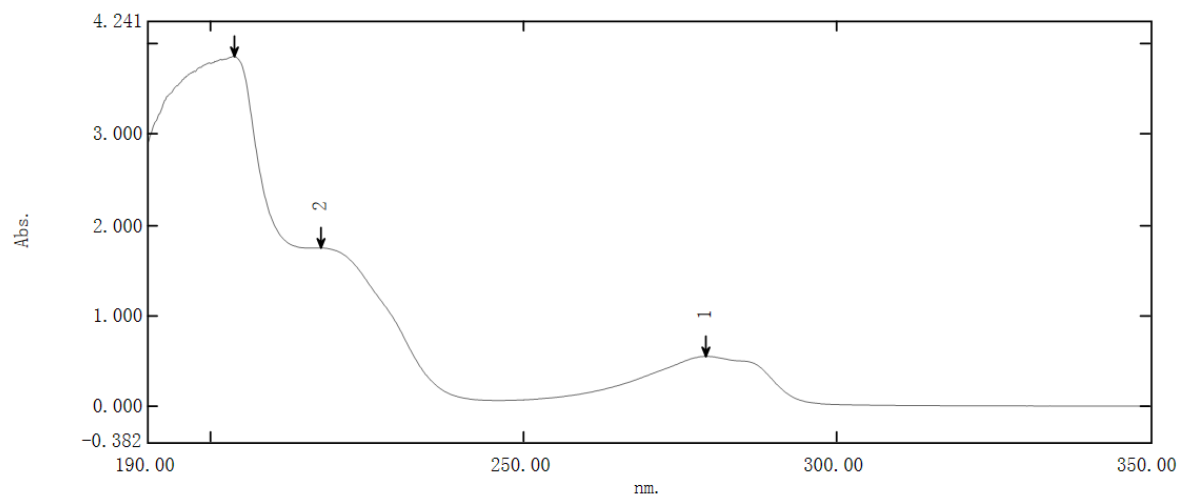

\begin{tabular}{|r|r|r|r|r|}
\hline No. & P/V & 波长(nm) & Abs. & 描述 \\
\hline 1 & $\mathbf{1}$ & 279.20 & 0.552 & \\
\hline 2 & $\mathbf{\uparrow}$ & 217.60 & 1.748 & \\
\hline 3 & $\mathbf{0}$ & 203.70 & 3.856 & \\
\hline 4 & $\mathbf{0}$ & 246.10 & 0.067 & \\
\hline 5 & $\mathbf{0}$ & 215.50 & 1.747 & \\
\hline
\end{tabular}

Figure S3. UV spectrum of 1 


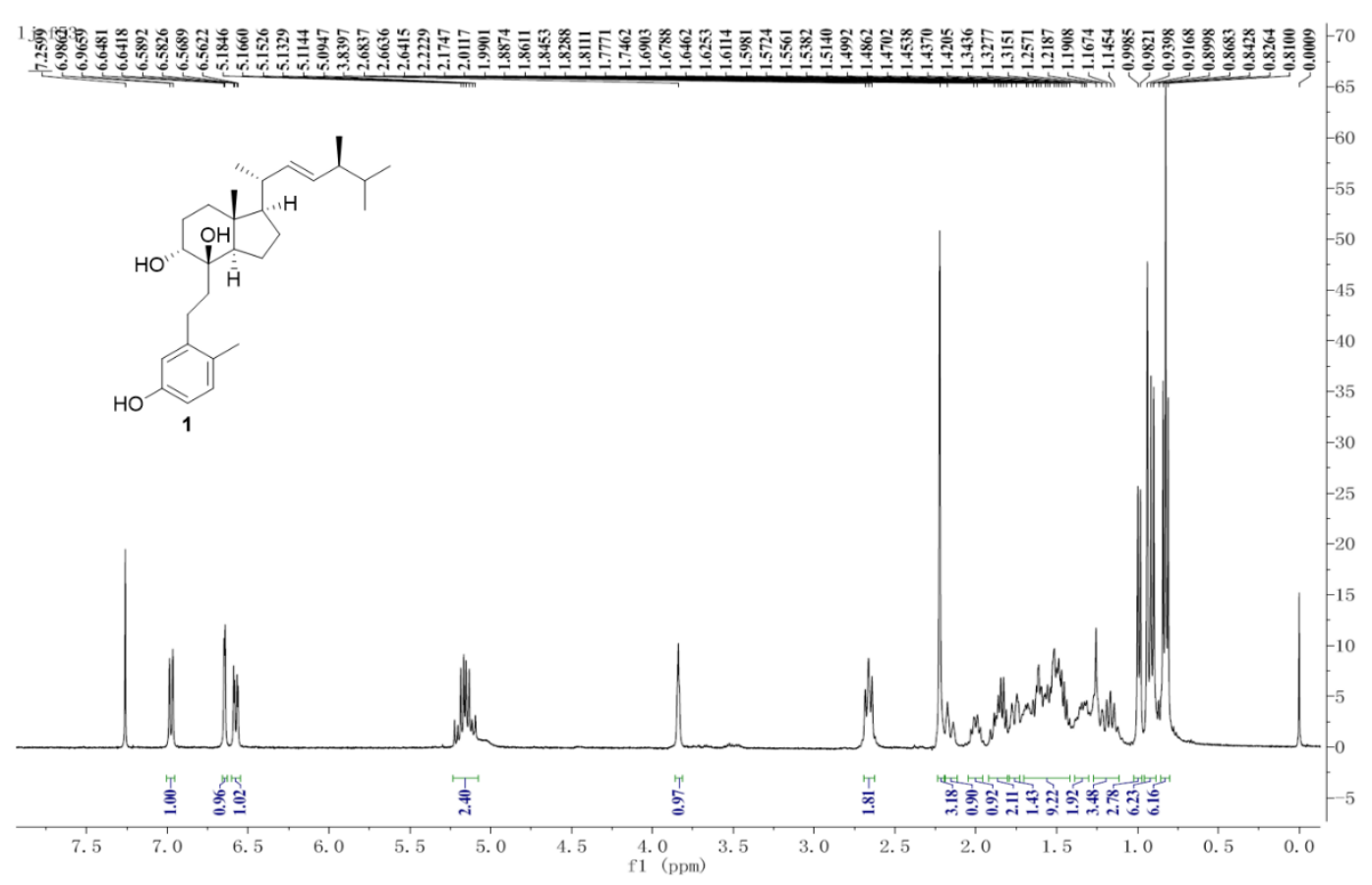

Figure S4. ${ }^{1} \mathrm{H} \mathrm{NMR}\left(600 \mathrm{MHz}, \mathrm{CDCl}_{3}\right)$ spectrum of $\mathbf{1}$

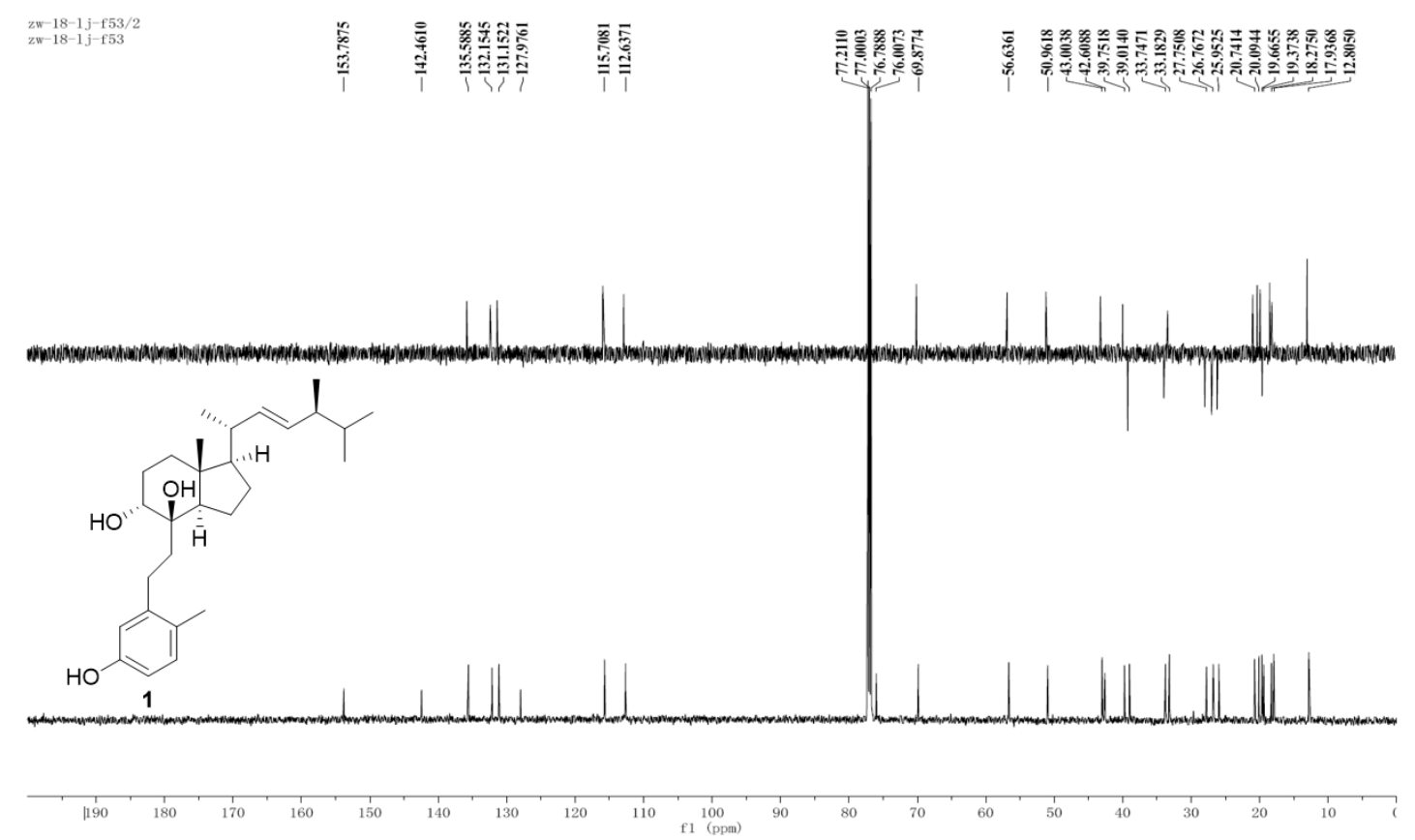

Figure S5. ${ }^{13} \mathrm{C}-\mathrm{NMR}$ and DEPT $\left(150 \mathrm{MHz}, \mathrm{CDCl}_{3}\right)$ spectrum of $\mathbf{1}$ 


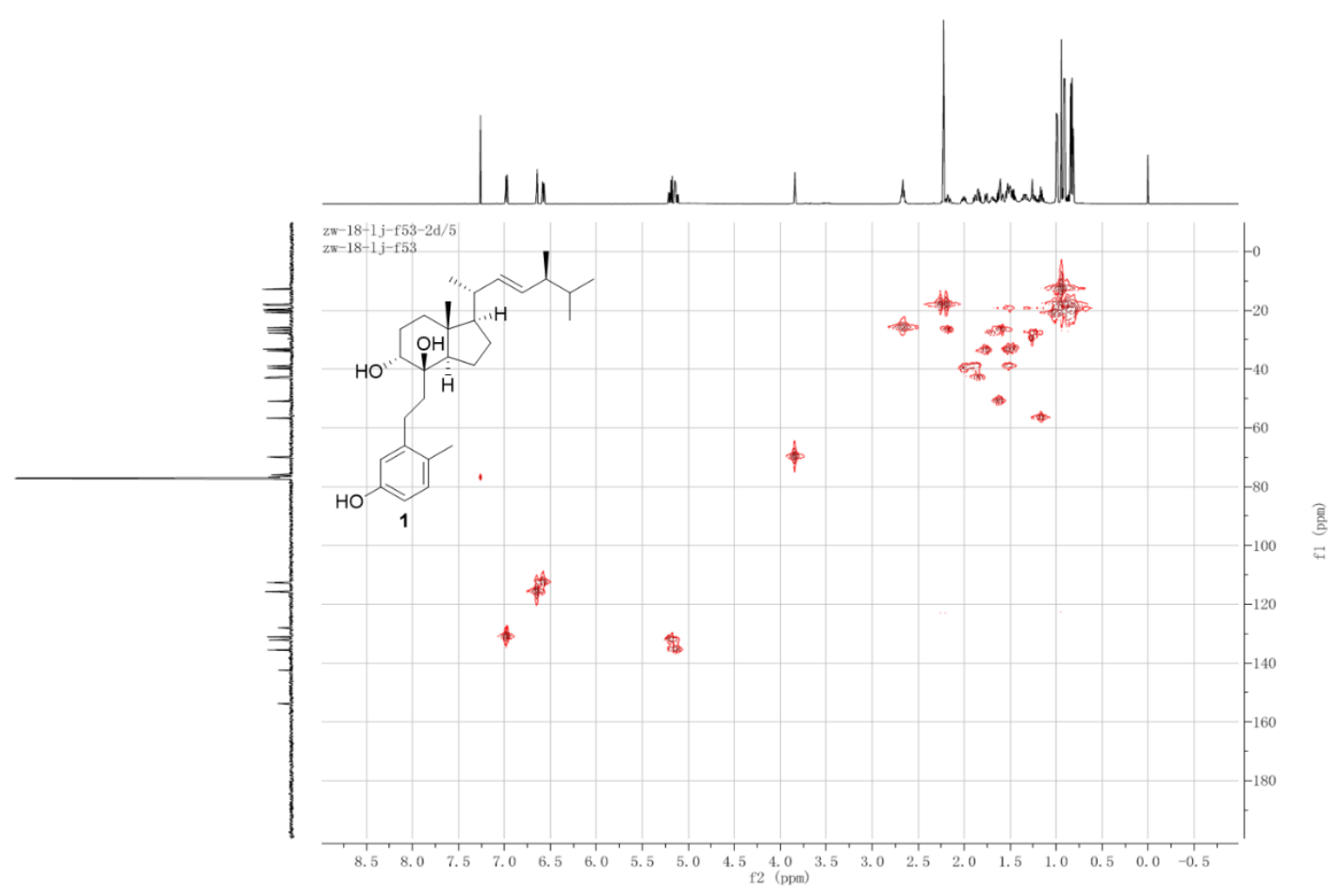

Figure S6. HSQC spectrum of 1 in $\mathrm{CDCl}_{3}$

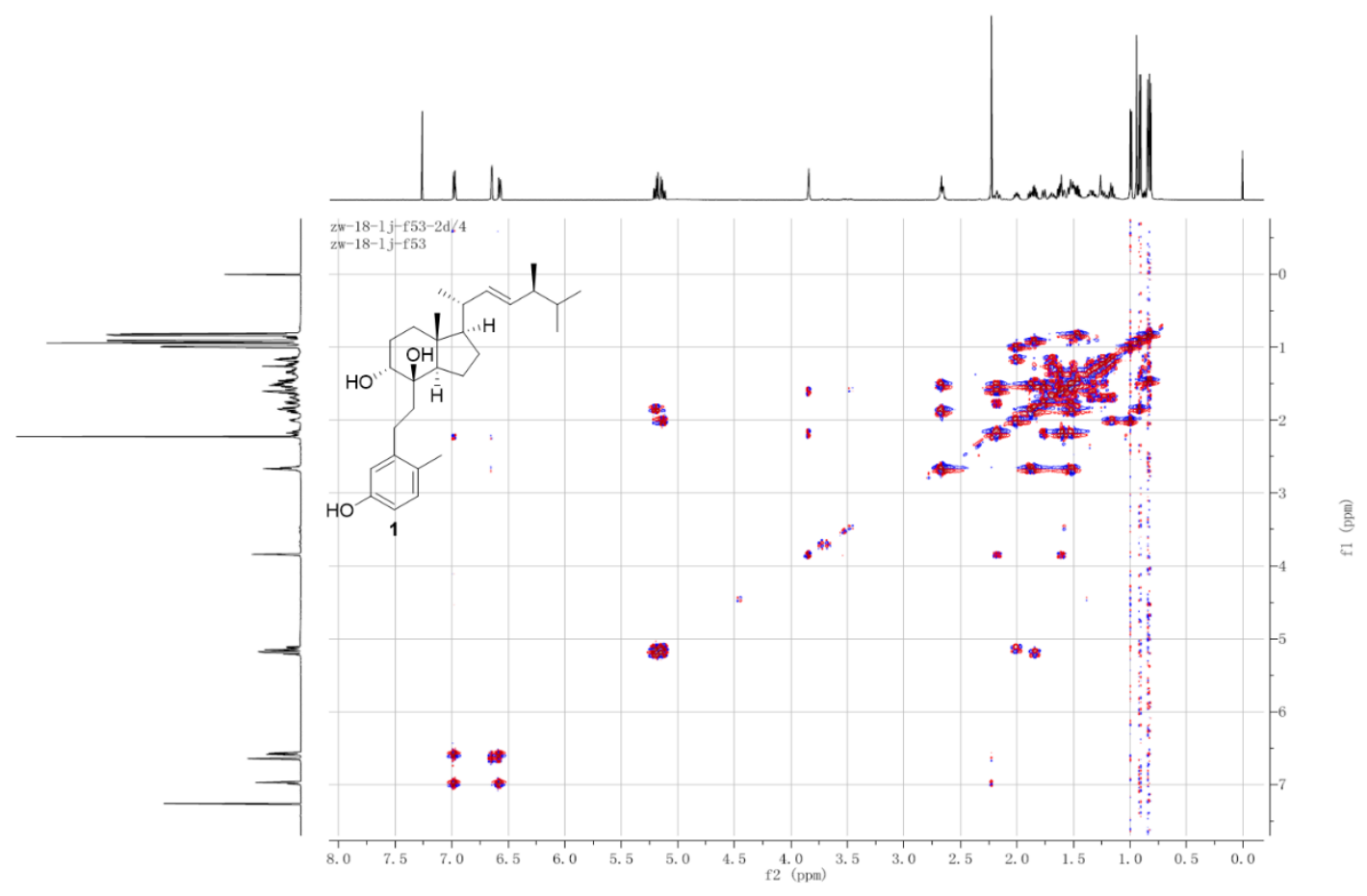

Figure S7. ${ }^{1} \mathrm{H}-{ }^{1} \mathrm{H}$ COSY spectrum of $\mathbf{1}$ in $\mathrm{CDCl}_{3}$ 


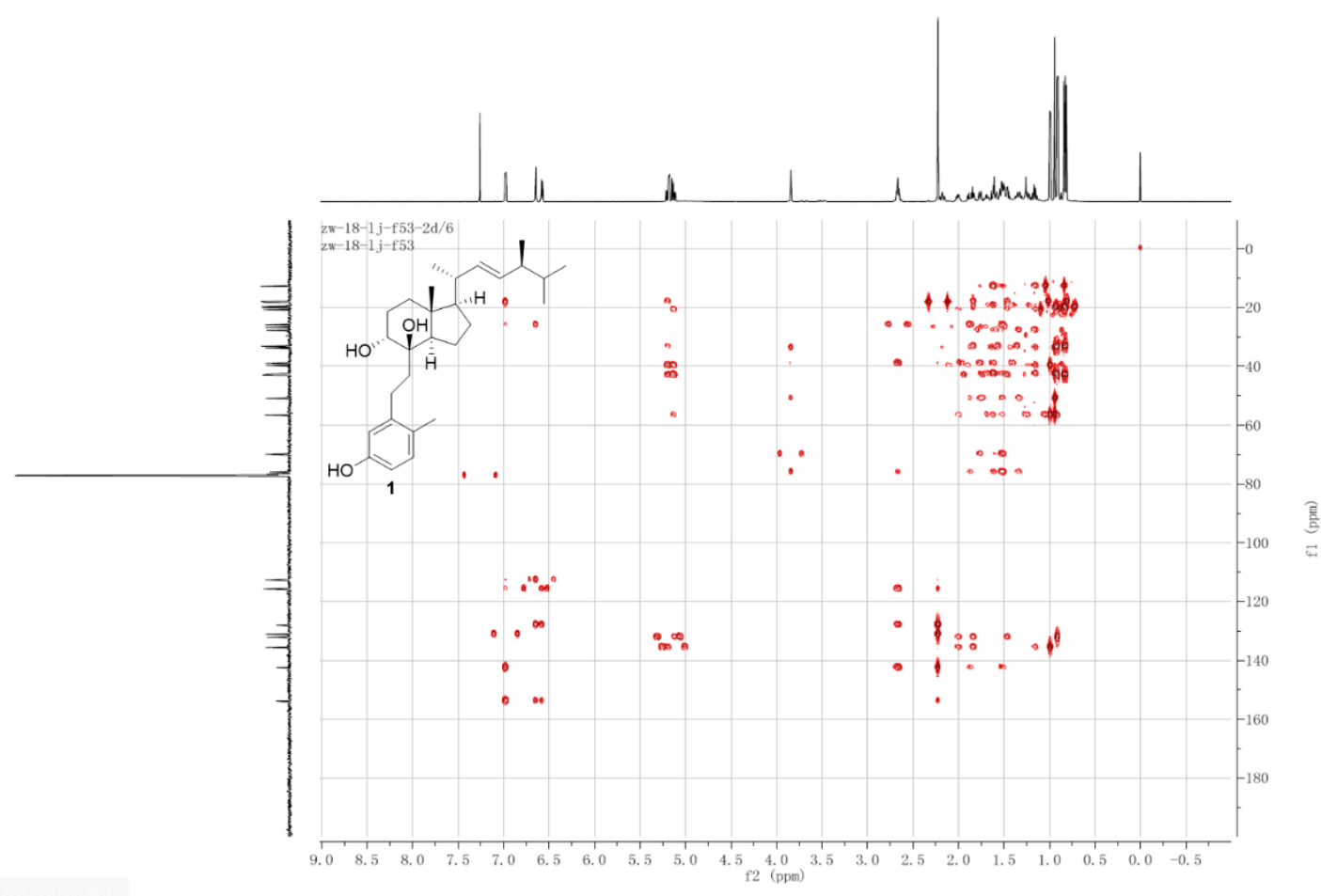

Figure S8. $\mathrm{HMBC}$ spectrum of $\mathbf{1}$ in $\mathrm{CDCl}_{3}$

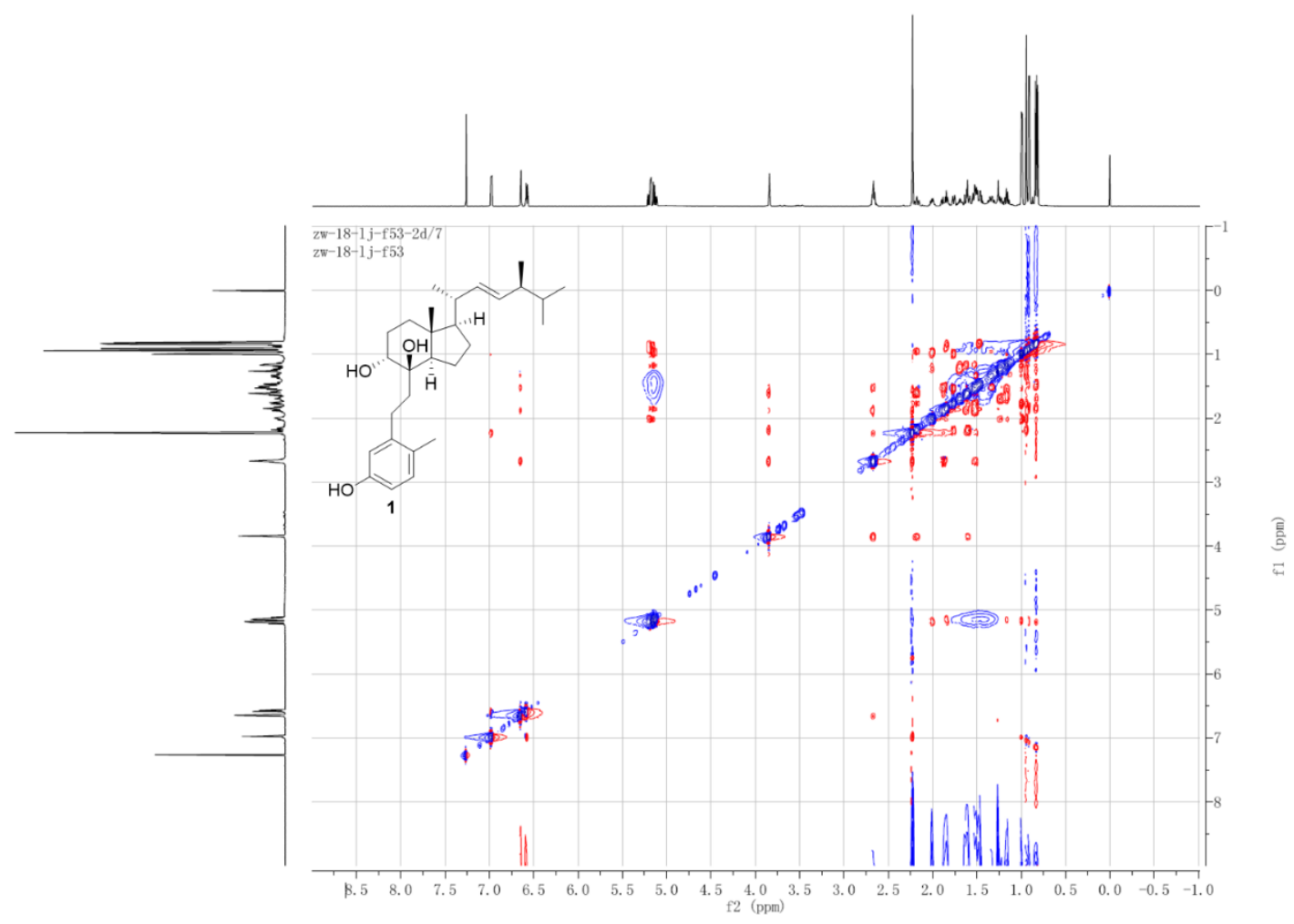

Figure S9. NOESY spectrum of $\mathbf{1}$ in $\mathrm{CDCl}_{3}$ 
定性分析报告

$\begin{array}{llll}\text { 数据文件名称 } & \text { F57-1-NEG.d } & \text { 样品名称 } & \\ \text { 样品类型 } & \text { Sample } & \text { 位置 } & \text { P1-D1 } \\ \text { 仪器名称 } & \text { Instrument 1 } & \text { 用户名 } & \\ \text { 采集方法 } & \text { TEST-NEG.m } & \text { 采集时间 } & \text { 3/12/2018 11:12:03 AM } \\ \text { IRM 校正状态 } & \text { Some Ions Missed } & \text { DA 方法 } & \text { lj.m } \\ \text { 注释 } & & & \\ \text { Sample Group } & \text { Info. } & & \end{array}$

User Spectra
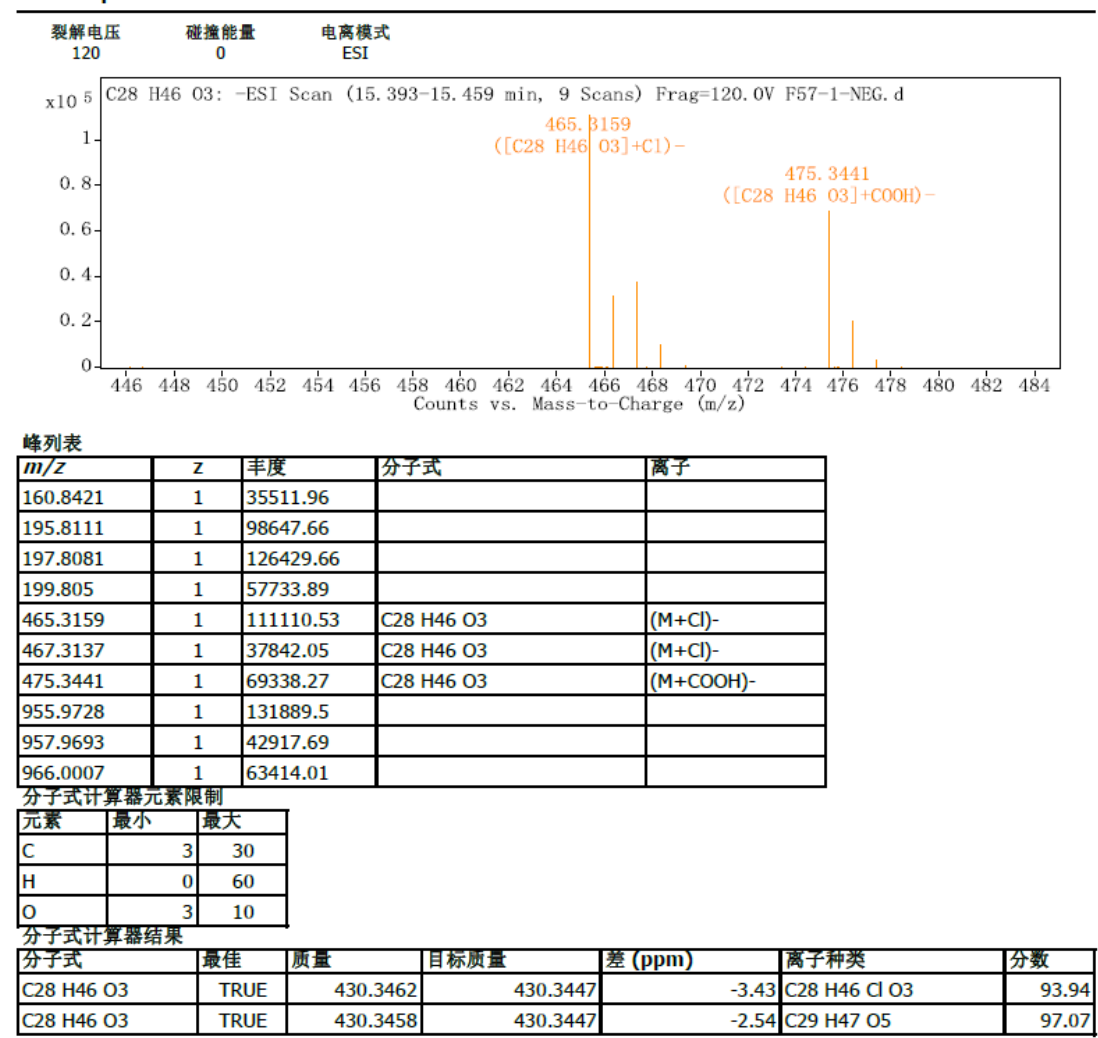

--- 报告结束 -- 
定性分析报告

\begin{tabular}{|c|c|c|}
\hline 数据文件名称 & F57-1-POS.d & 样品名称 \\
\hline 样品类型 & Sample & P1-D1 \\
\hline 仪器名称 & Instrument 1 & 用户名 \\
\hline 采集方法 & TEST-POS.m & 采集时间 2018/3/12 8:38:16 (UTC+08:00) \\
\hline $\begin{array}{l}\text { IRM 校正状态 } \\
\text { 注释 }\end{array}$ & 成功 & DA 方法 Default.m \\
\hline Sample Group & & Info. \\
\hline 采集时间 (当地) & $\begin{array}{l}\text { 2018/3/12 8:38:16 } \\
\text { (UTC+08:00) }\end{array}$ & \\
\hline
\end{tabular}

化合物

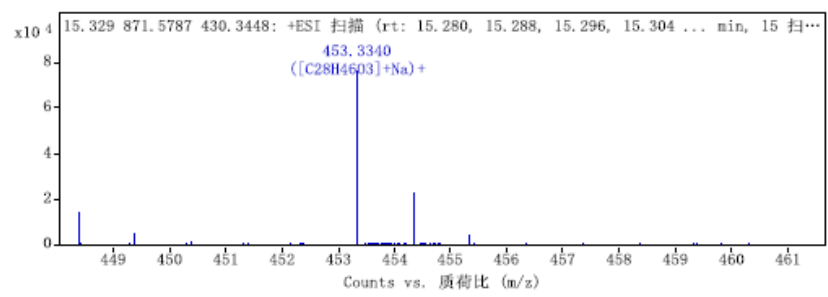

\begin{tabular}{|c|c|c|c|c|}
\hline$m / z$ & $z$ & 聿度 & 份子式 & 畕子 \\
\hline 453.334 & 1 & 76336.59 & $\mathrm{C} 28 \mathrm{H} 46 \mathrm{O} 3$ & $(\mathrm{M}+\mathrm{Na})+$ \\
\hline 454.3374 & 1 & 22865.12 & $\mathrm{C} 28 \mathrm{H} 46 \mathrm{O} 3$ & $(\mathrm{M}+\mathrm{Na})+$ \\
\hline 455.34 & 1 & 3890.2 & $\mathrm{C} 28 \mathrm{H} 46 \mathrm{O} 3$ & $(\mathrm{M}+\mathrm{Na})+$ \\
\hline 456.3452 & 1 & 630.16 & $\mathrm{C} 28 \mathrm{H} 46 \mathrm{O} 3$ & $(\mathrm{M}+\mathrm{Na})+$ \\
\hline
\end{tabular}

- 据告结束

Figure S10. HRESI-MS spectrum of 2 


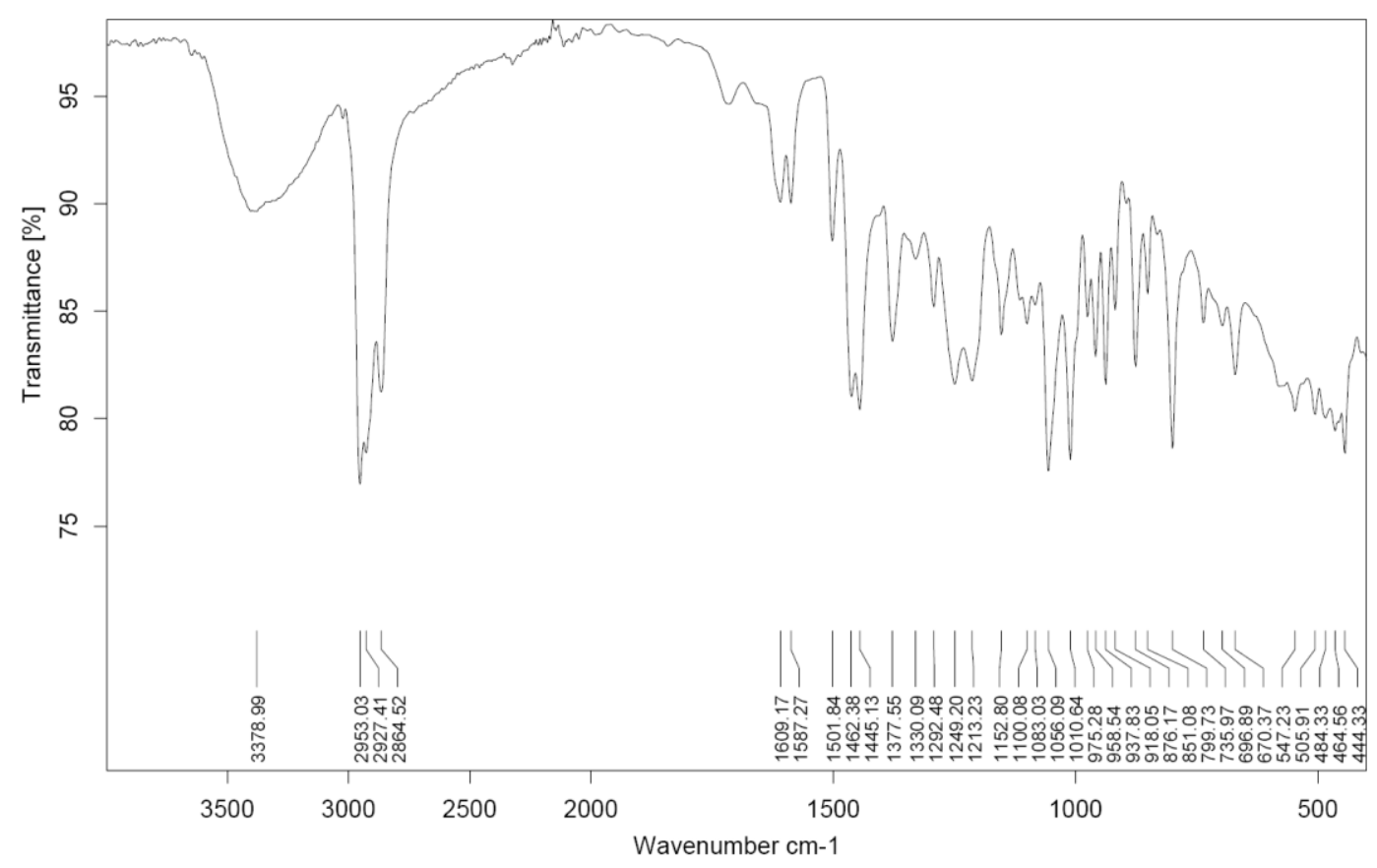

D:IDATAI-军大IF57-1.0 F57-1 Instrument type and / or accessory $01 / 06 / 2018$

Page $1 / 1$

Figure S11. IR spectrum of 2

State Key Laboratory of Organometallic Chemistry Shanghai Institute of Organic Chemistry

Chinese Academy of Sciences

光谱测定报告

打印日期时间: 2018/03/21 15:23:12

文件名： f57-1-RawData

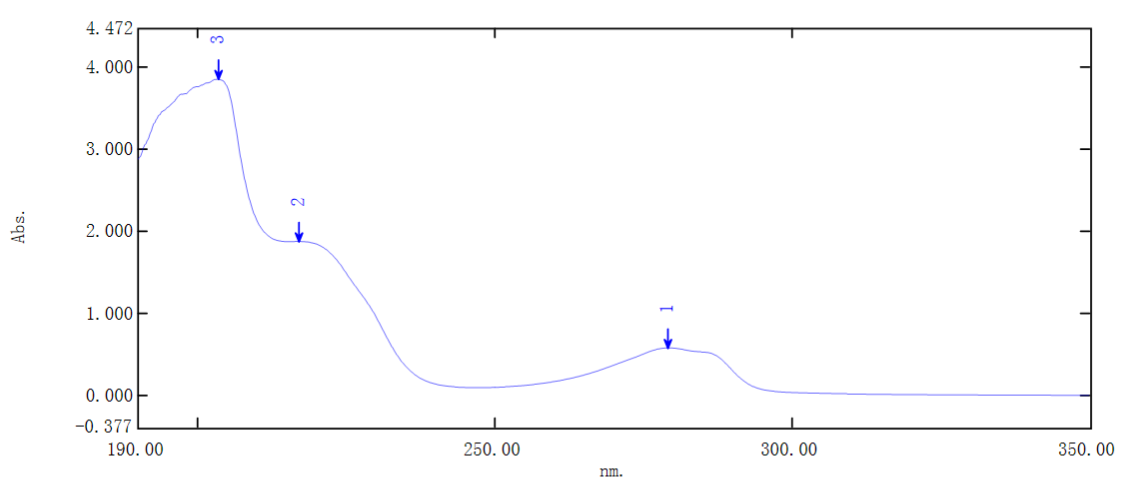

\begin{tabular}{|r|r|r|r|r|}
\hline No. & P/V & 波长(nm) & Abs. & 描述 \\
\hline 1 & $\mathbf{(}$ & 279.20 & 0.586 & \\
\hline 2 & $\mathbf{(}$ & 217.10 & 1.882 & \\
\hline 3 & $\mathbf{(}$ & 203.50 & 3.859 & \\
\hline 4 & $\mathbf{0}$ & 247.00 & 0.102 & \\
\hline 5 & $\mathbf{0}$ & 215.00 & 1.880 & \\
\hline
\end{tabular}

Figure S12. UV spectrum of 2 


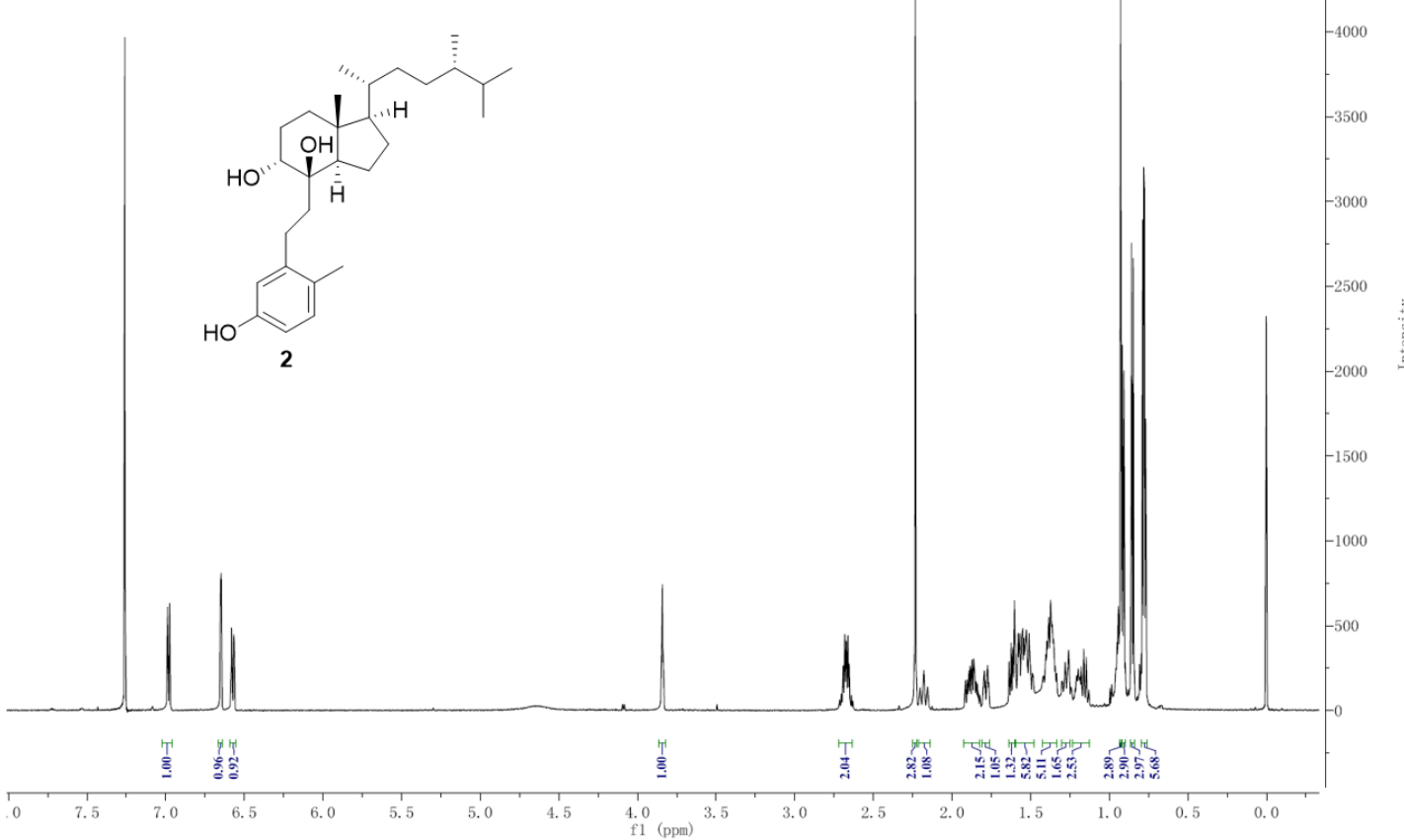

Figure S13. ${ }^{1} \mathrm{H}$ NMR $\left(600 \mathrm{MHz}, \mathrm{CDCl}_{3}\right)$ spectrum of 2

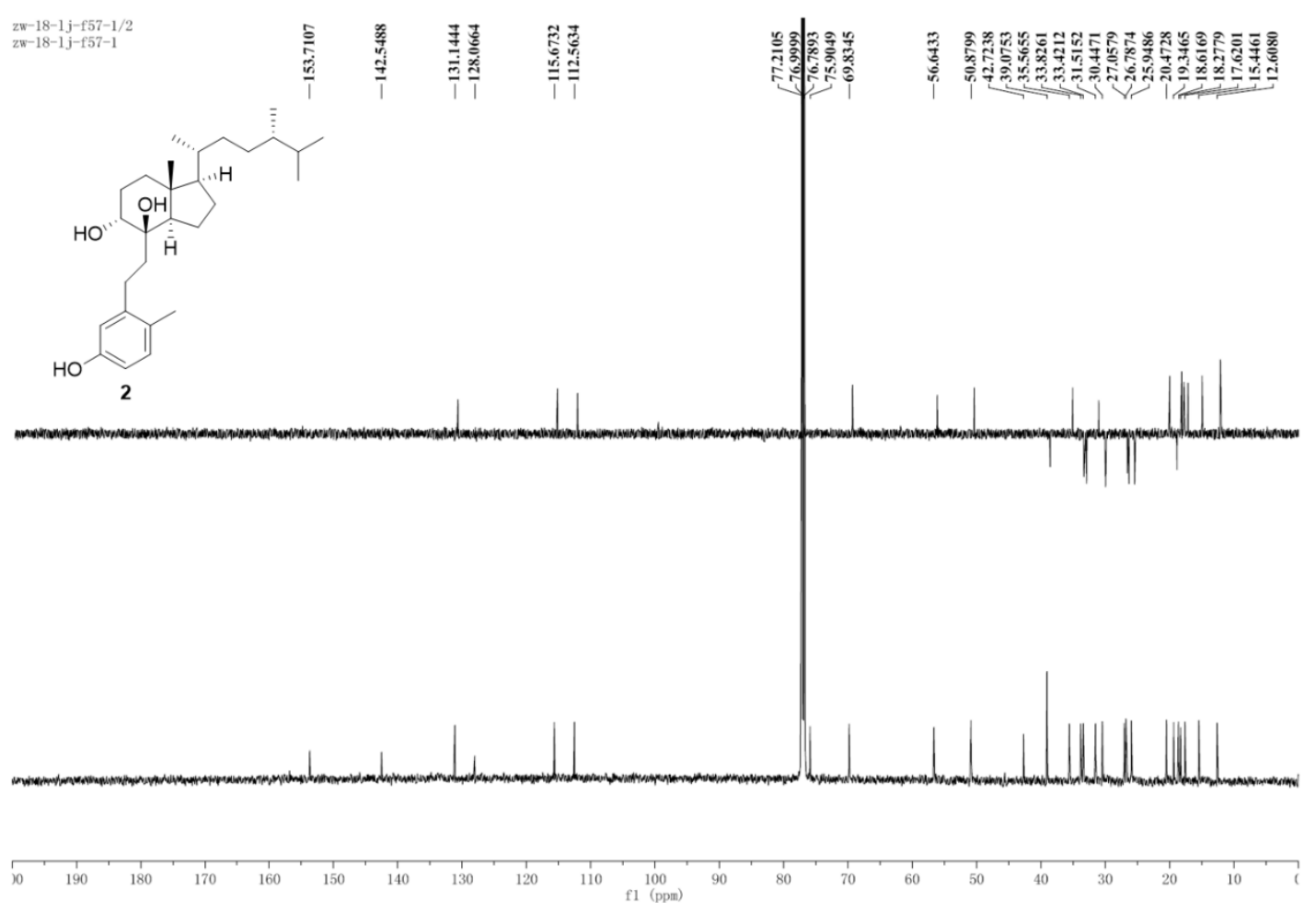

Figure S14. ${ }^{13} \mathrm{C}-\mathrm{NMR}$ and DEPT $\left(150 \mathrm{MHz}, \mathrm{CDCl}_{3}\right)$ spectrum of 2 


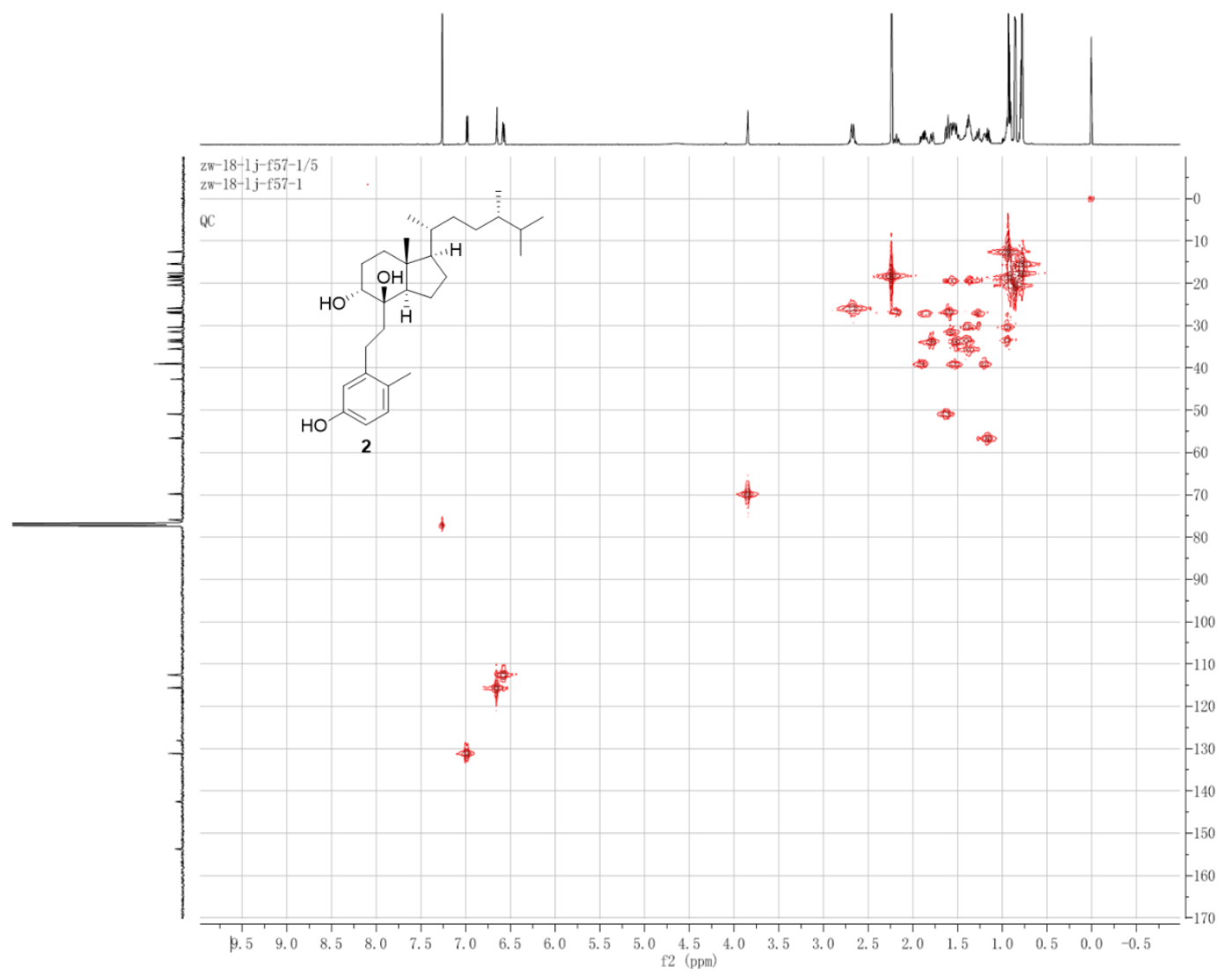

Figure S15. HSQC spectrum of 2 in $\mathrm{CDCl}_{3}$

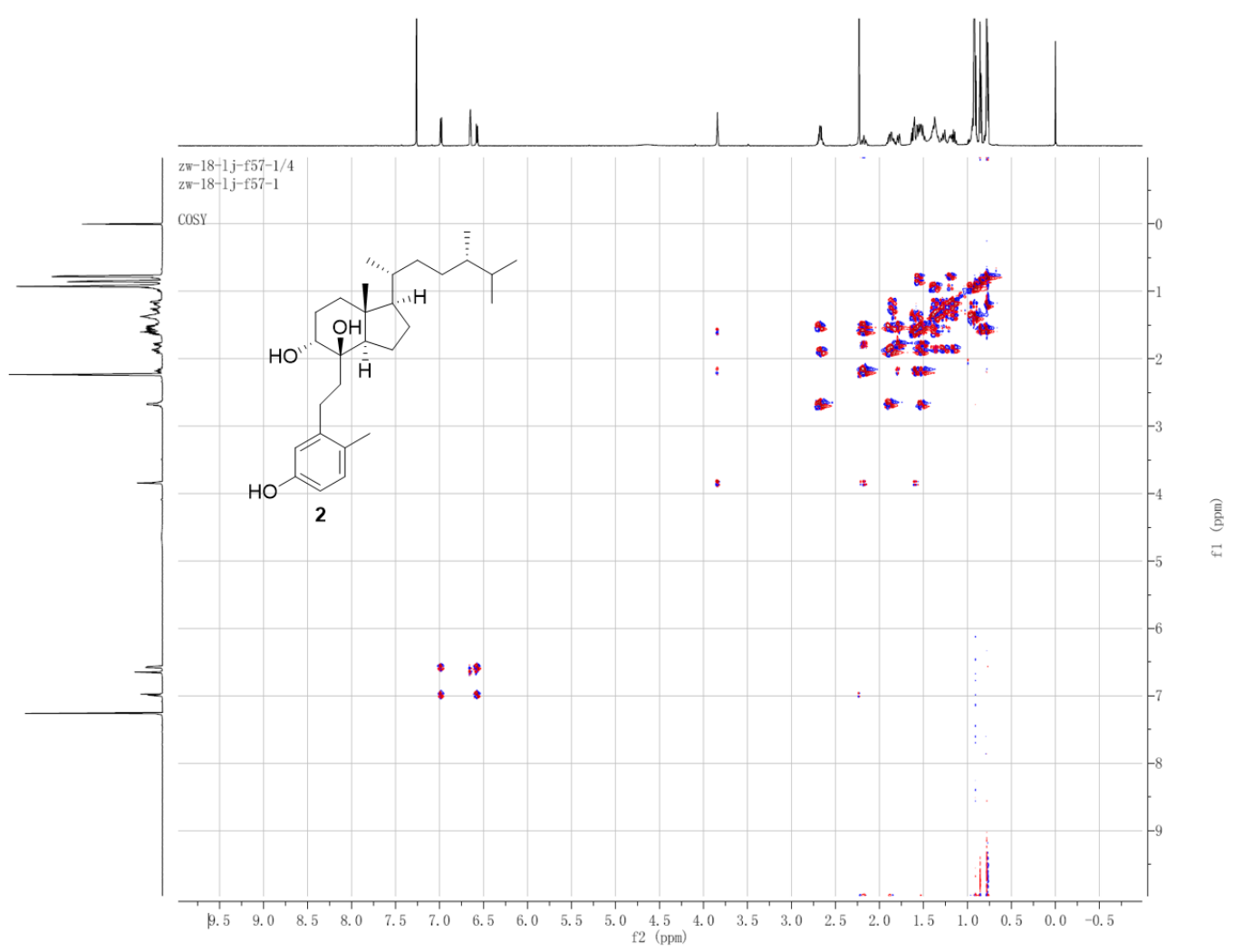

Figure S16. ${ }^{1} \mathrm{H}-{ }^{1} \mathrm{H}$ COSY spectrum of 2 in $\mathrm{CDCl}_{3}$ 


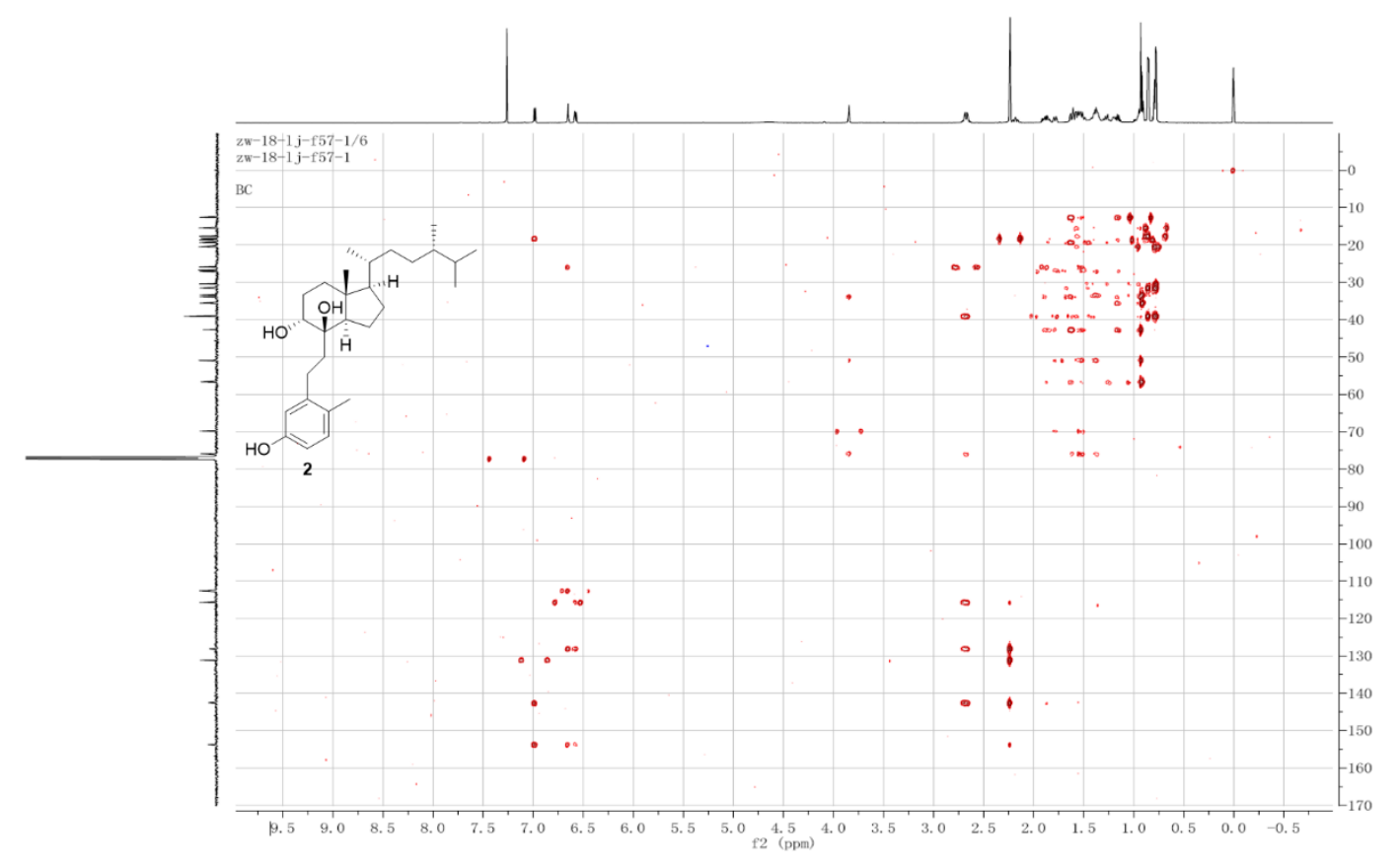

Figure S17. $\mathrm{HMBC}$ spectrum of $\mathbf{2}$ in $\mathrm{CDCl}_{3}$

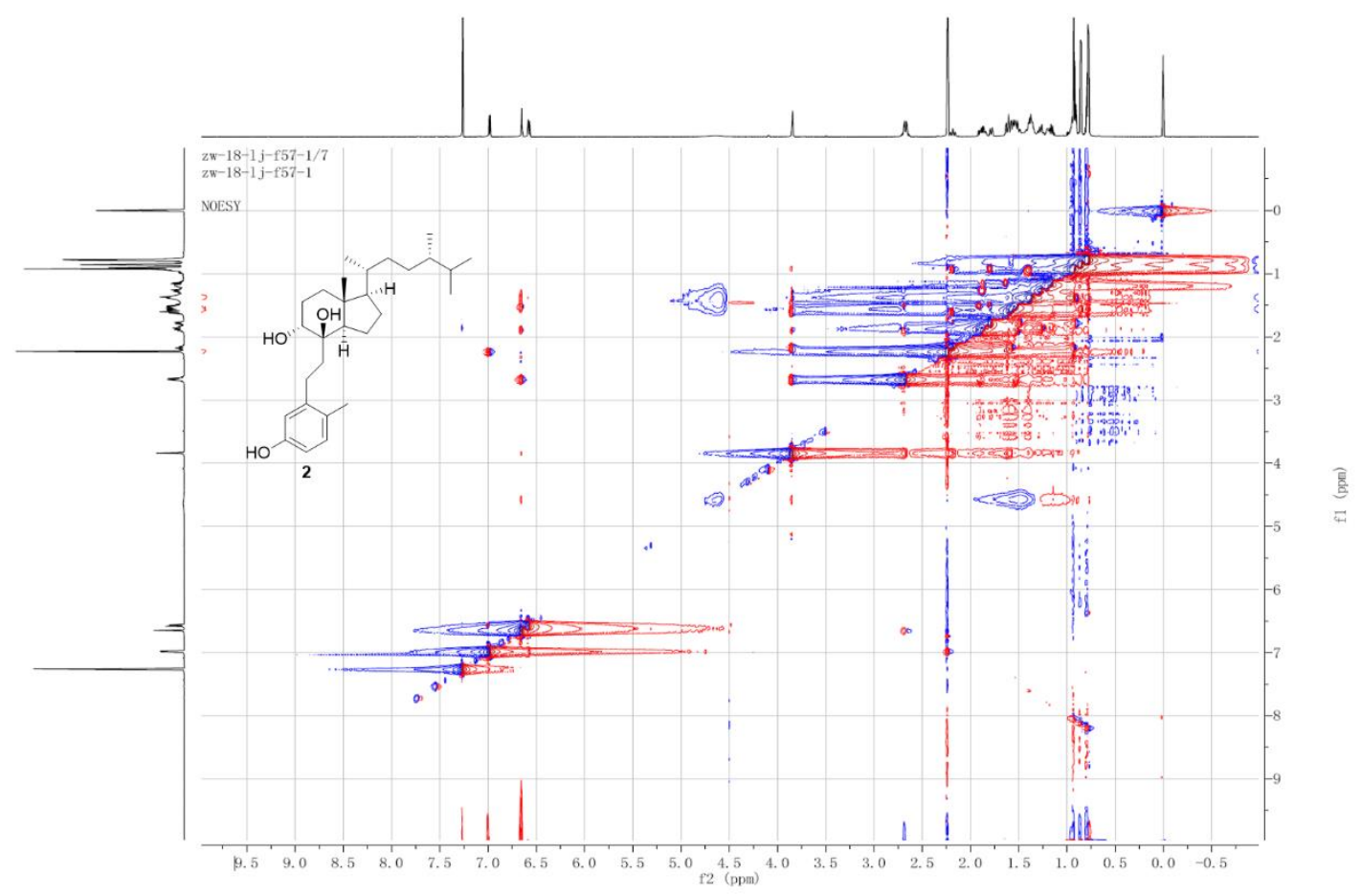

Figure S18. NOESY spectrum of $\mathbf{2}$ in $\mathrm{CDCl}_{3}$ 
定性分析报告

\begin{tabular}{llll} 
数据文件名称 & F38-NEG.d & 样品名称 & \\
样品类型 & Sample & 位置 & P1-D5 \\
仪器名称 & Instrument 1 & 用户名 & \\
采集方法 & TEST-NEG.m & 采集时间 & 3/11/2018 11:11:40 PM \\
IRM 校正状态 & Some Ions Missed & DA 方法 & lj.m \\
注释 & & & \\
Sample Group & \multirow{2}{*}{ Info. } & & \\
& & &
\end{tabular}

User Spectra

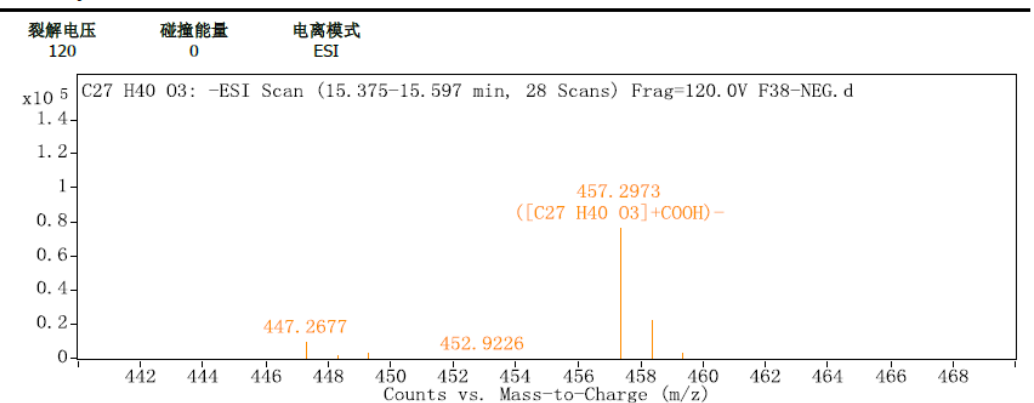

峰列表
\begin{tabular}{|l|l|l|l|l|}
$\boldsymbol{m} / \boldsymbol{z}$ & $\mathrm{Z}$ & 丰度 & 分子式 & 离子 \\
\hline 100.9341 & 1 & 20075.61 & & \\
\hline 144.9235 & 1 & 11200.38 & & \\
\hline 149.9945 & 1 & 10199.29 & & \\
\hline 447.2677 & 1 & 10519.43 & & $(\mathrm{M}+\mathrm{COOH})-$ \\
\hline 457.2973 & 1 & 77140.89 & $\mathrm{C} 27 \mathrm{H} 40 \mathrm{O} 3$ & $(\mathrm{M}+\mathrm{COOH})-$ \\
\hline 458.3 & 1 & 23323.68 & $\mathrm{C} 27 \mathrm{H} 40 \mathrm{O} 3$ & \\
\hline 805.9849 & 1 & 24160.33 & & \\
\hline 955.9699 & 1 & 21661.13 & & \\
\hline 966.0007 & 1 & 197718.47 & & \\
\hline 967.0023 & 1 & 39489.95 & & \\
\hline
\end{tabular}

公子式计算㗊元素限制 39489.95

完素聚小等大

\begin{tabular}{|l|r|r|}
\hline $\mathrm{C}$ & 3 & 30 \\
\hline $\mathrm{H}$ & 0 & 60 \\
\hline
\end{tabular}

\begin{tabular}{|l|r|c|}
\hline 0 & 3 & 10 \\
\hline
\end{tabular}

分子式计算器结

C27 H40 03

最佳 1 原

412.298

目标质量

离子种类 412.2977

--- 报告结束 --- 
定性分析报告

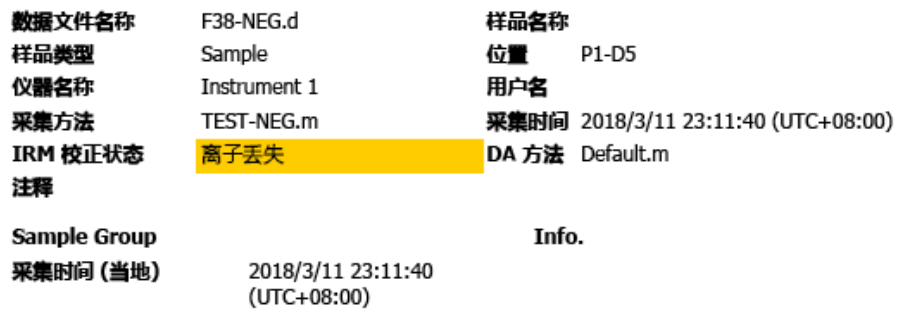

\section{化合物}

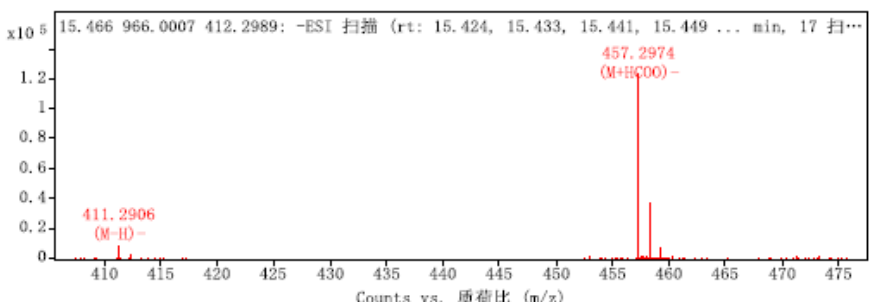

\begin{tabular}{|c|c|c|c|c|}
\hline $\mathrm{m} / \mathrm{z}$ & $\mathrm{z}$ & 丰变 & 分子式 & 高子 \\
\hline 411.2906 & 1 & 7880.08 & $\mathrm{C} 27 \mathrm{H} 40 \mathrm{O} 3$ & $(\mathrm{M}-\mathrm{H})-$ \\
\hline 412.2941 & 1 & 2278.53 & $\mathrm{C} 27 \mathrm{H} 40 \mathrm{O} 3$ & $(M-H)-$ \\
\hline 413.2965 & 1 & 348.57 & $\mathrm{C} 27 \mathrm{H} 40 \mathrm{O} 3$ & $(M-H)-$ \\
\hline 457.2974 & 1 & 123291.74 & $\mathrm{C} 27 \mathrm{H} 40 \mathrm{O} 3$ & $(\mathrm{M}+\mathrm{HCOO})-$ \\
\hline 458.3001 & 1 & 37308.39 & $\mathrm{C} 27 \mathrm{H} 40 \mathrm{O} 3$ & $(\mathrm{M}+\mathrm{HCOO})-$ \\
\hline 459.3027 & 1 & 6368.55 & $\mathrm{C} 27 \mathrm{H} 40 \mathrm{O} 3$ & $(\mathrm{M}+\mathrm{HCOO})-$ \\
\hline 460.3051 & 1 & 914.98 & $\mathrm{C} 27 \mathrm{H} 40 \mathrm{O} 3$ & $(\mathrm{M}+\mathrm{HCOO})-$ \\
\hline 471.3104 & 1 & 662.24 & $\mathrm{C} 27 \mathrm{H} 40 \mathrm{O} 3$ & $(\mathrm{M}+\mathrm{CH} 3 \mathrm{COO})-$ \\
\hline 472.3151 & 1 & 248.23 & $\mathrm{C} 2 \mathrm{HH} 40 \mathrm{O} 3$ & $(\mathrm{M}+\mathrm{CH} 3 \mathrm{COO})-$ \\
\hline 473.3195 & 1 & 857.66 & $\mathrm{C} 27 \mathrm{H} 40 \mathrm{O} 3$ & $(\mathrm{M}+\mathrm{CH} 3 \mathrm{COO})-$ \\
\hline
\end{tabular}

-- 报告结束 --

Figure S19. HRESI-MS spectrum of 3 

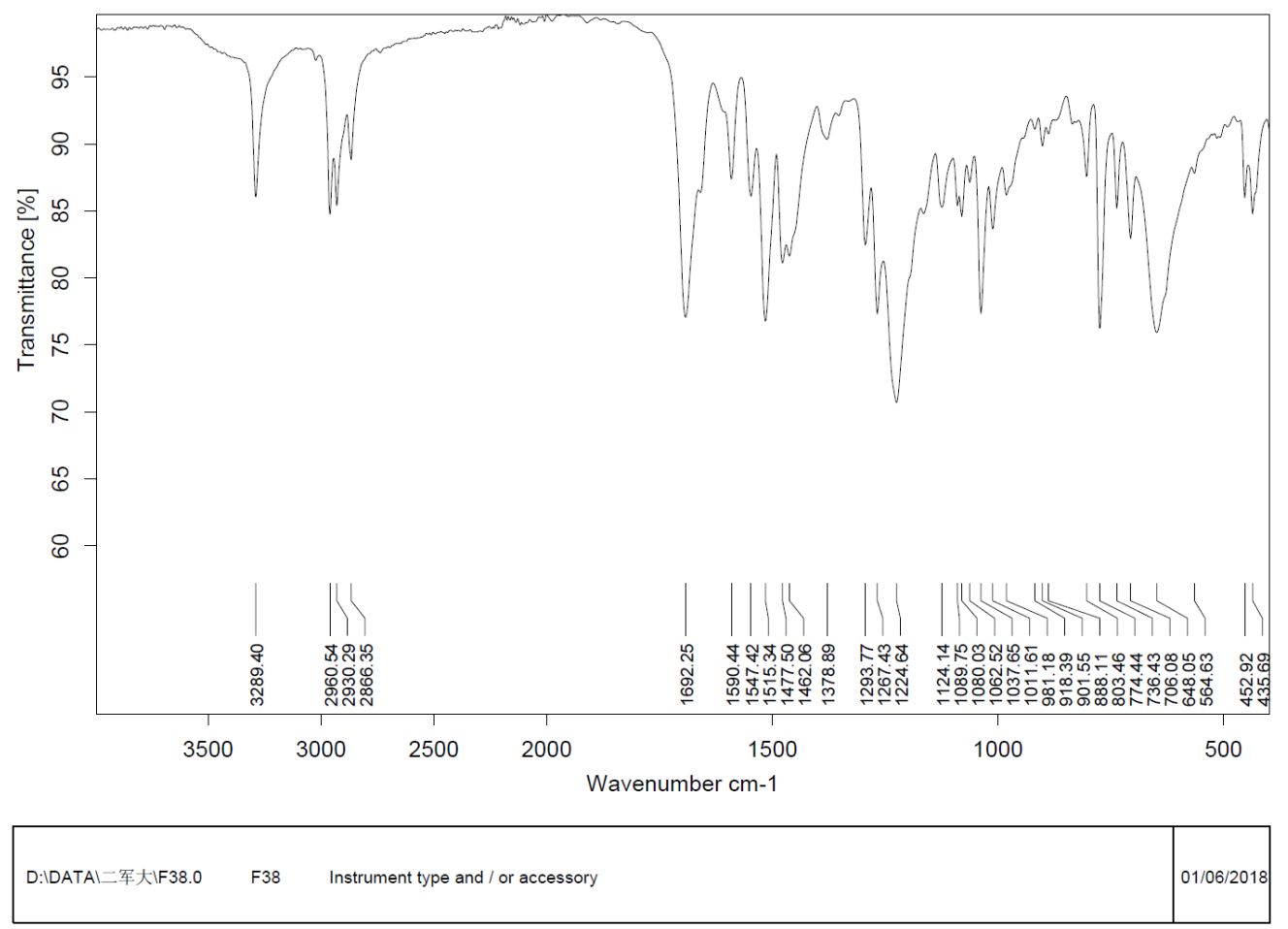

Page 1/1

Figure S20. IR spectrum of 3

\section{State Key Laboratory of Organometallic Chemistry Shanghai Institute of Organic Chemistry \\ Chinese Academy of Sciences}

光谱测定报告

打印日期时间： 2018/03/21 15.32.01

文件名： f38-3-RawData

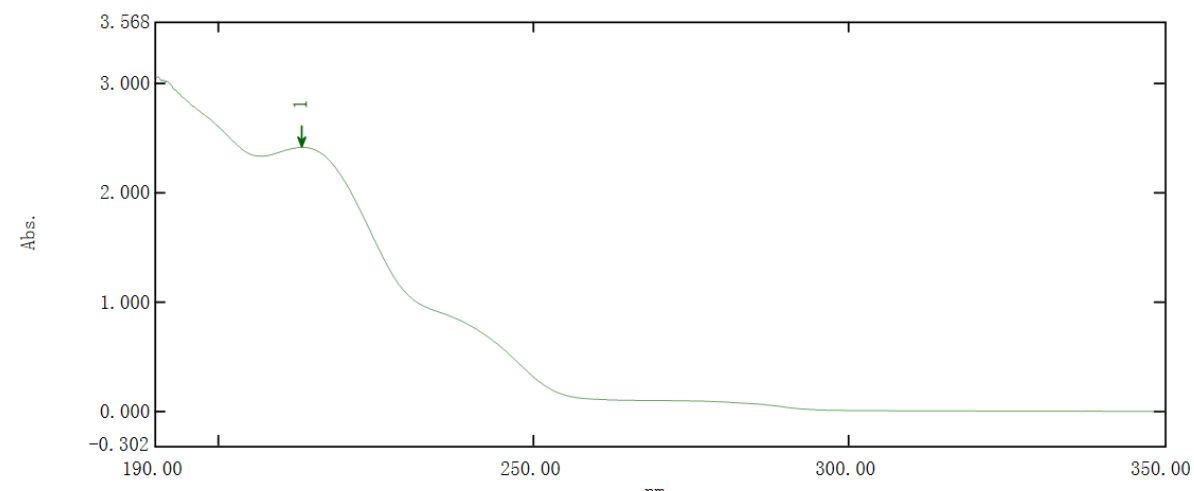

\begin{tabular}{|r|r|r|r|r|}
\hline No. & P/V & 波长(nm) & \multicolumn{1}{|c|}{ Abs. } & 描述 \\
\hline 1 & $\mathbf{(}$ & 213.30 & 2.423 & \\
\hline 2 & $\mathbf{0}$ & 207.00 & 2.343 & \\
\hline
\end{tabular}

Figure S21. UV spectrum of $\mathbf{3}$ 


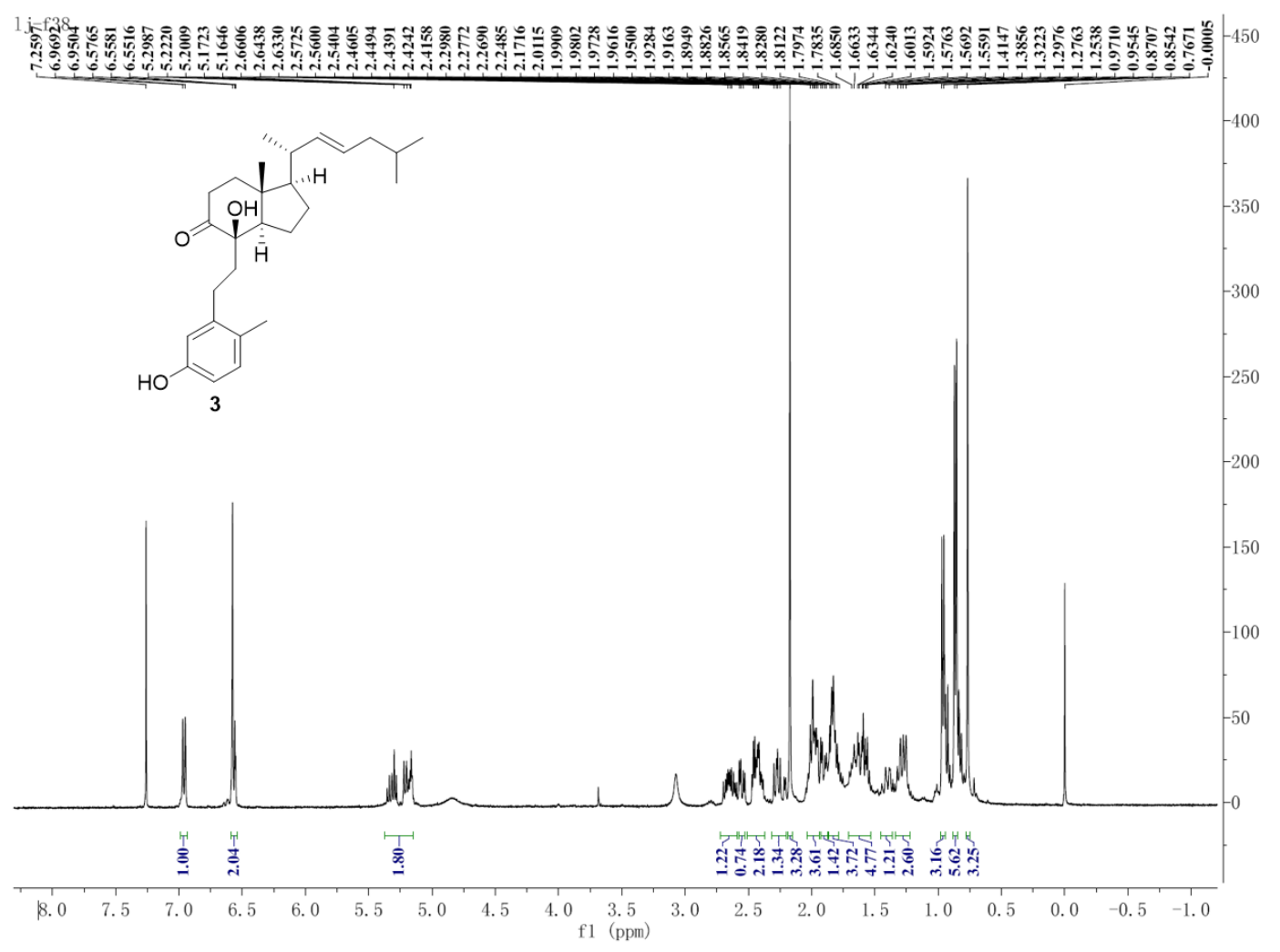

Figure S22. ${ }^{1} \mathrm{H}$ NMR $\left(600 \mathrm{MHz}, \mathrm{CDCl}_{3}\right)$ spectrum of $\mathbf{3}$
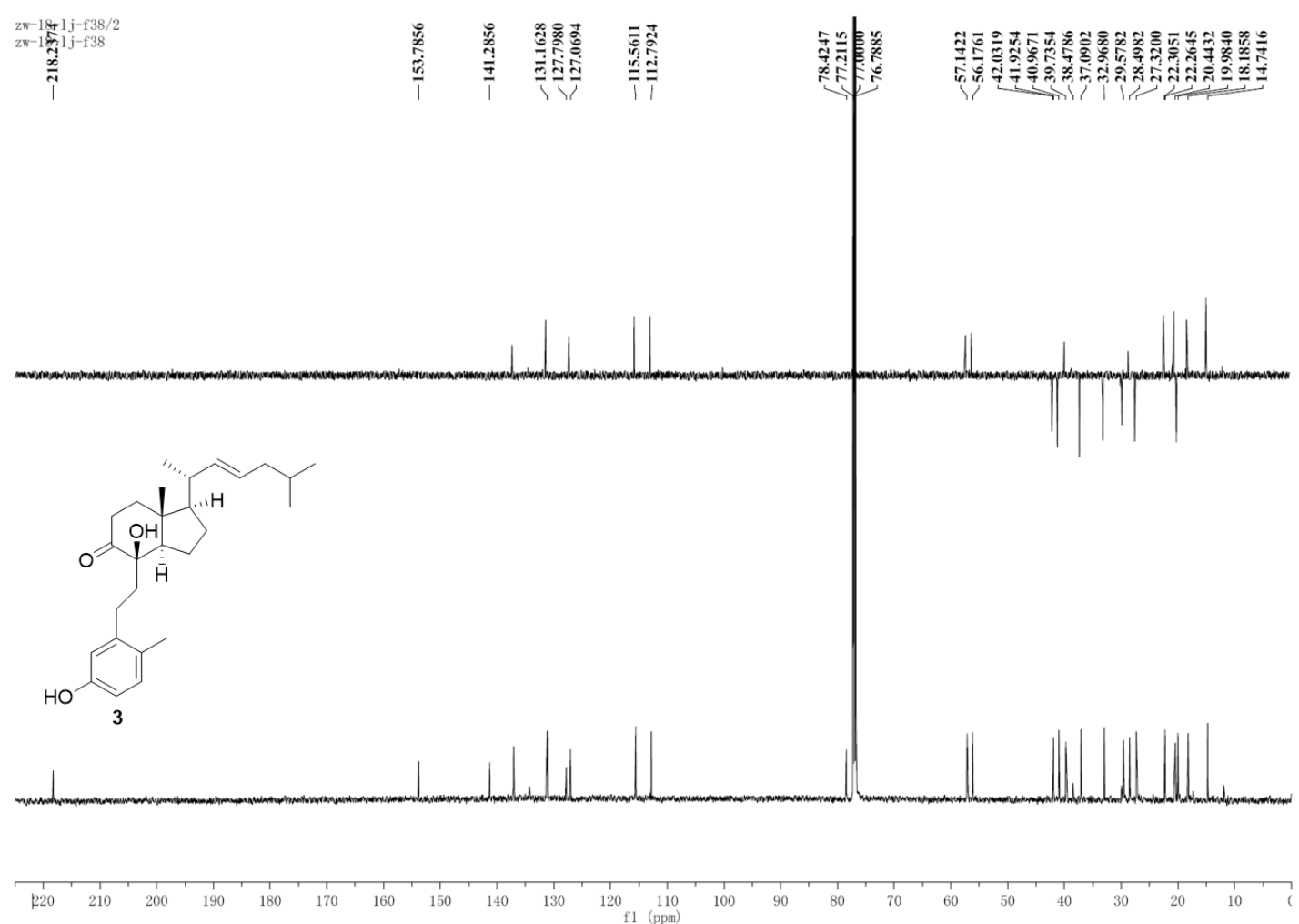

Figure S23. ${ }^{13} \mathrm{C}-\mathrm{NMR}$ and DEPT $\left(150 \mathrm{MHz}, \mathrm{CDCl}_{3}\right)$ spectrum of $\mathbf{3}$ 


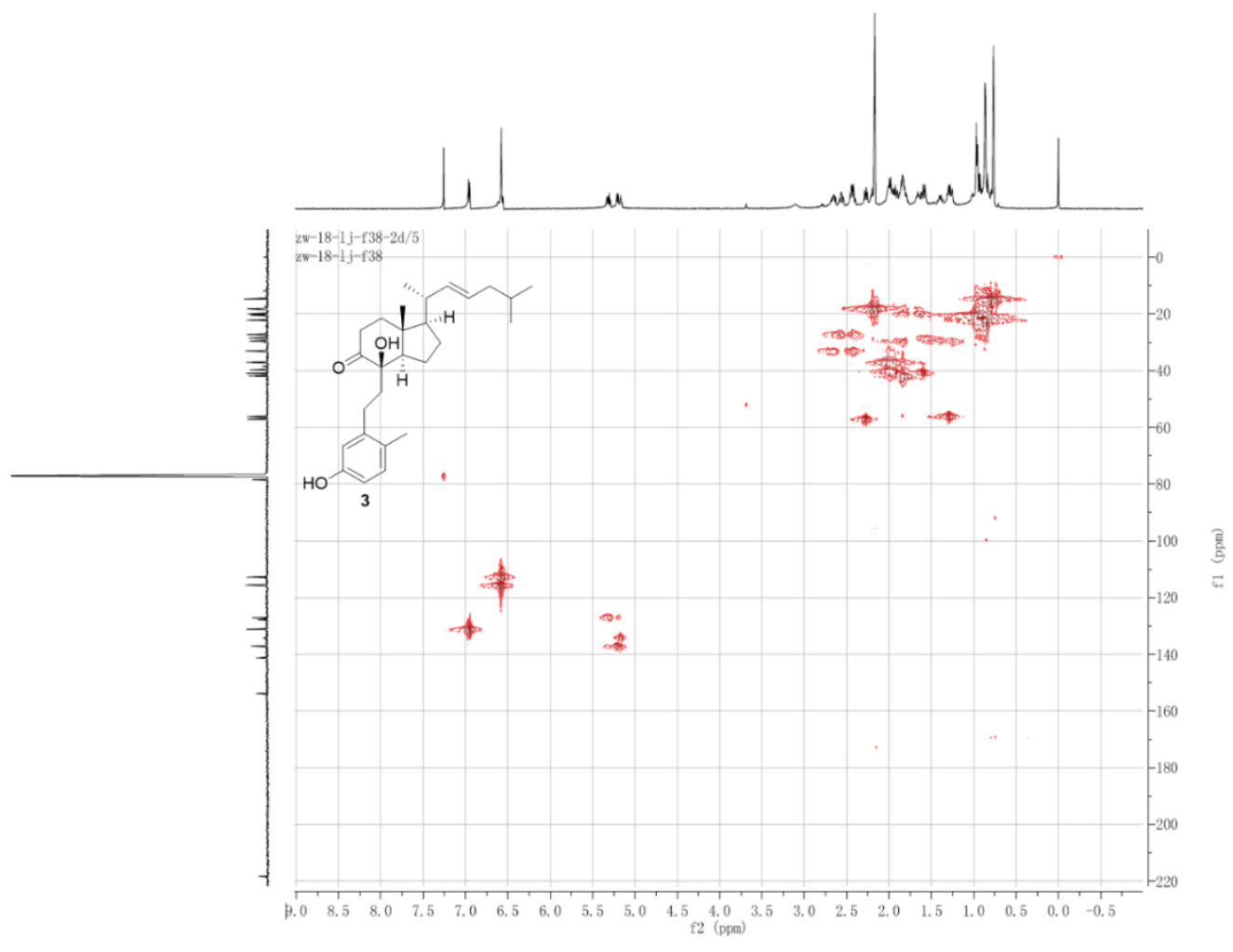

Figure S24. $\mathrm{HSQC}$ spectrum of $\mathbf{3}$ in $\mathrm{CDCl}_{3}$

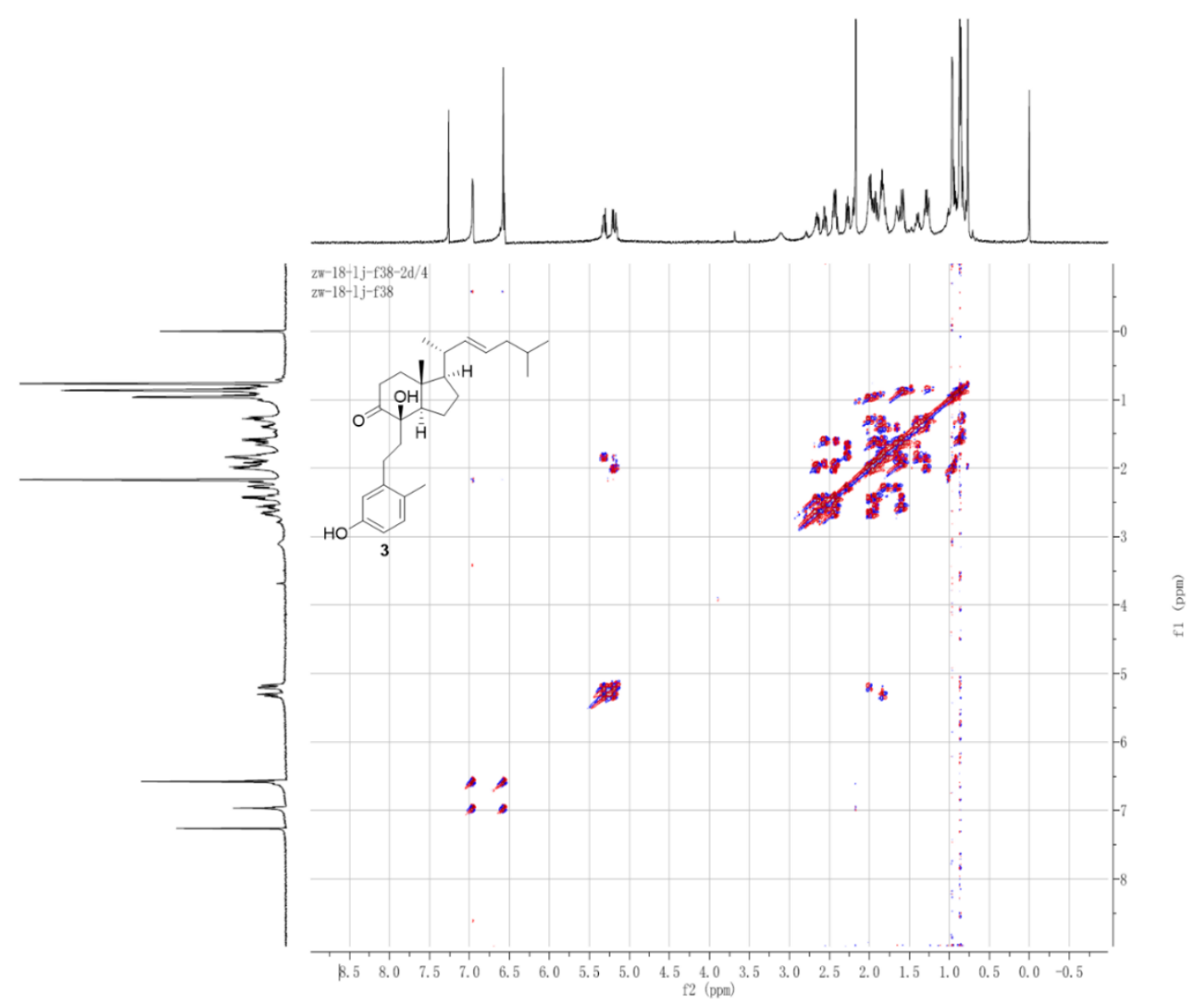

Figure S25. ${ }^{1} \mathrm{H}-{ }^{1} \mathrm{H}$ COSY spectrum of $\mathbf{3}$ in $\mathrm{CDCl}_{3}$ 


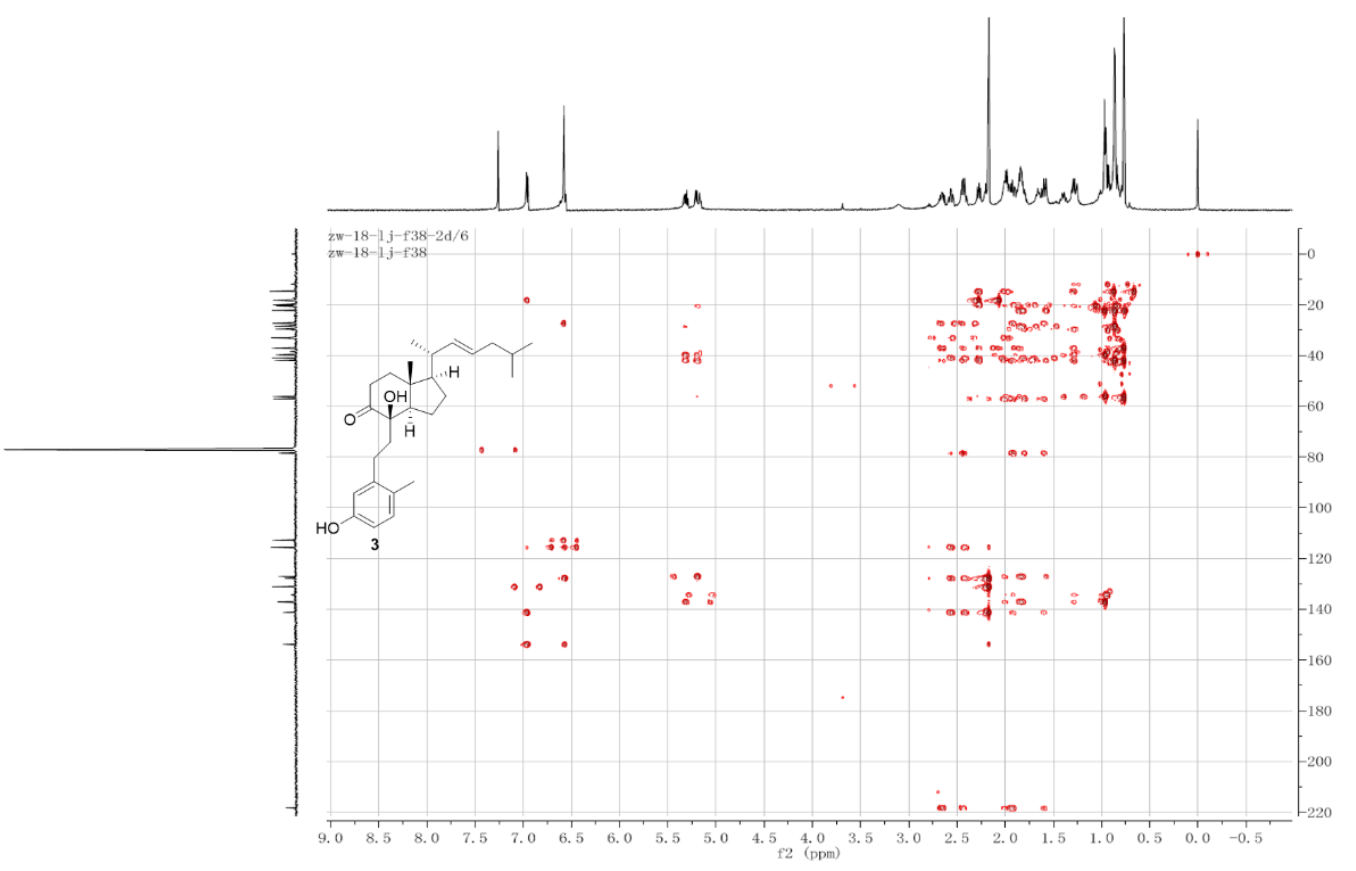

Figure S26. $\mathrm{HMBC}$ spectrum of $\mathbf{3}$ in $\mathrm{CDCl}_{3}$

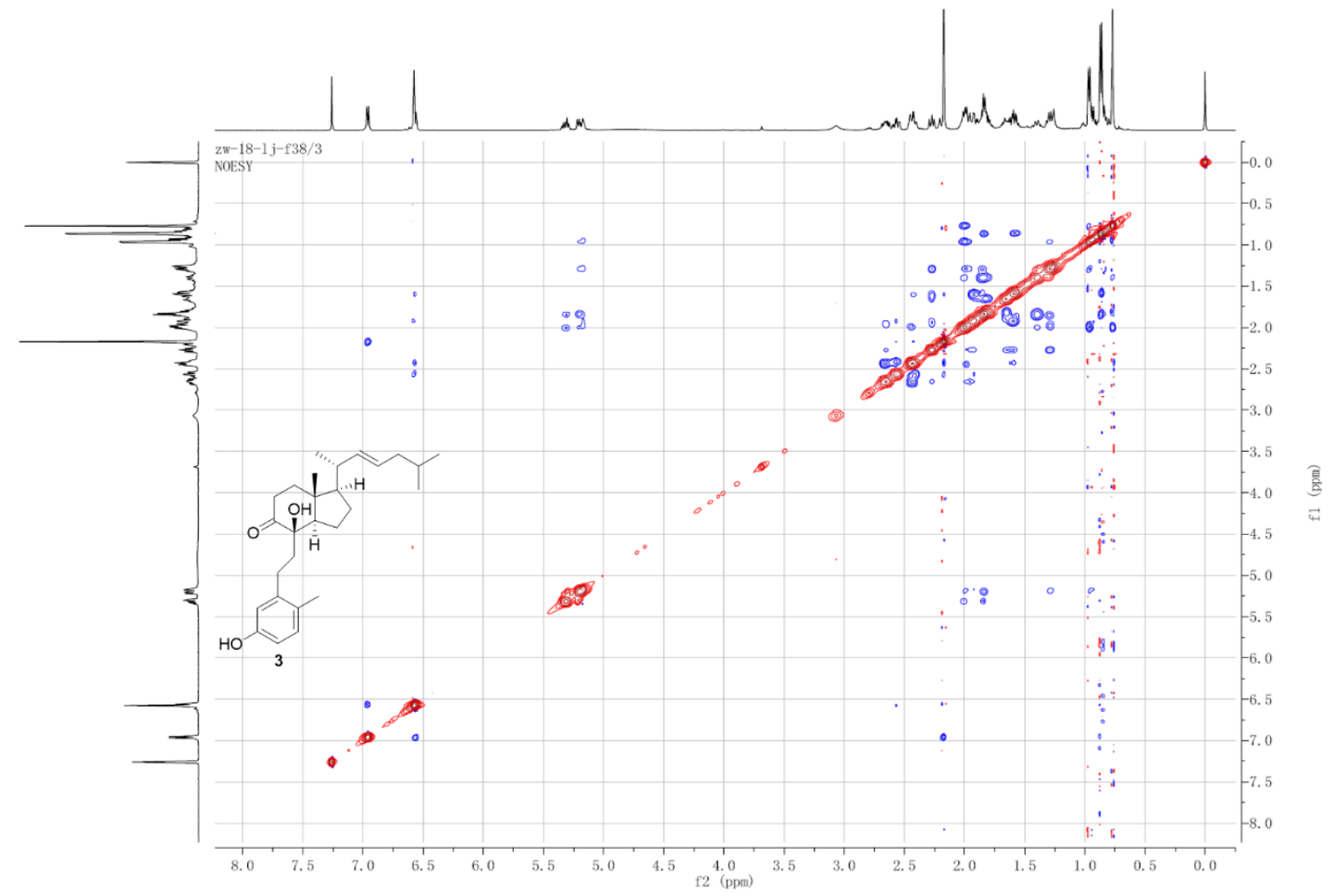

Figure S27. NOESY spectrum of $\mathbf{3}$ in $\mathrm{CDCl}_{3}$ 


\section{定性分析报告}

$\begin{array}{llll}\text { 数据文件名称 } & \text { F55-POS.d } & \text { 样品名称 } & \\ \text { 样品类型 } & \text { Sample } & \text { 位置 } & \text { P1-D6 } \\ \text { 仪器名称 } & \text { Instrument } 1 & \text { 用户名 } & \\ \text { 采集方法 } & \text { TEST-POS.m } & \text { 采集时间 } & \text { 3/12/2018 10:20:35 AM } \\ \text { IRM 校正状态 } & \text { Success } & \text { DA 方法 } & \text { lj.m }\end{array}$

注释

Sample Group Info.

User Spectra
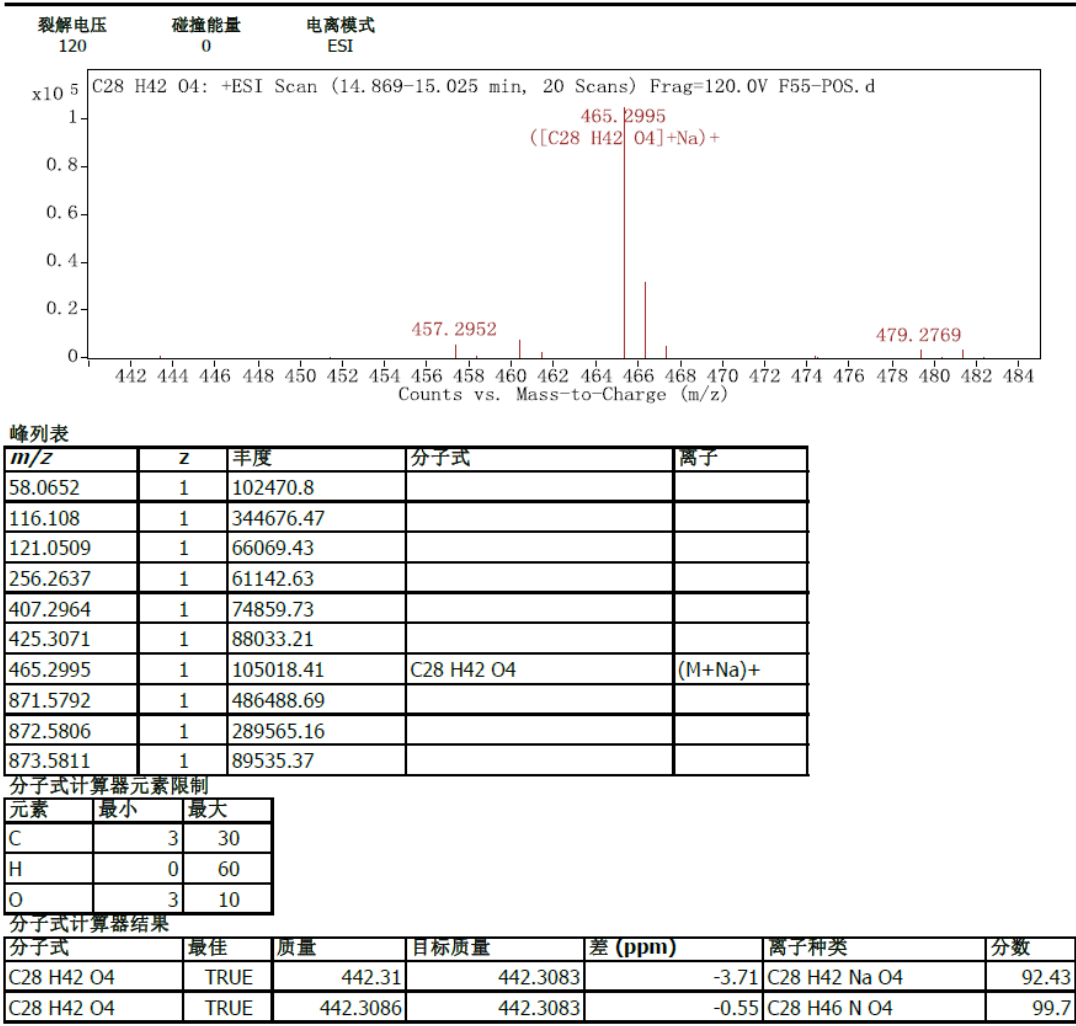

--- 报告结束 --

Figure S28. HRESI-MS spectrum of 4 


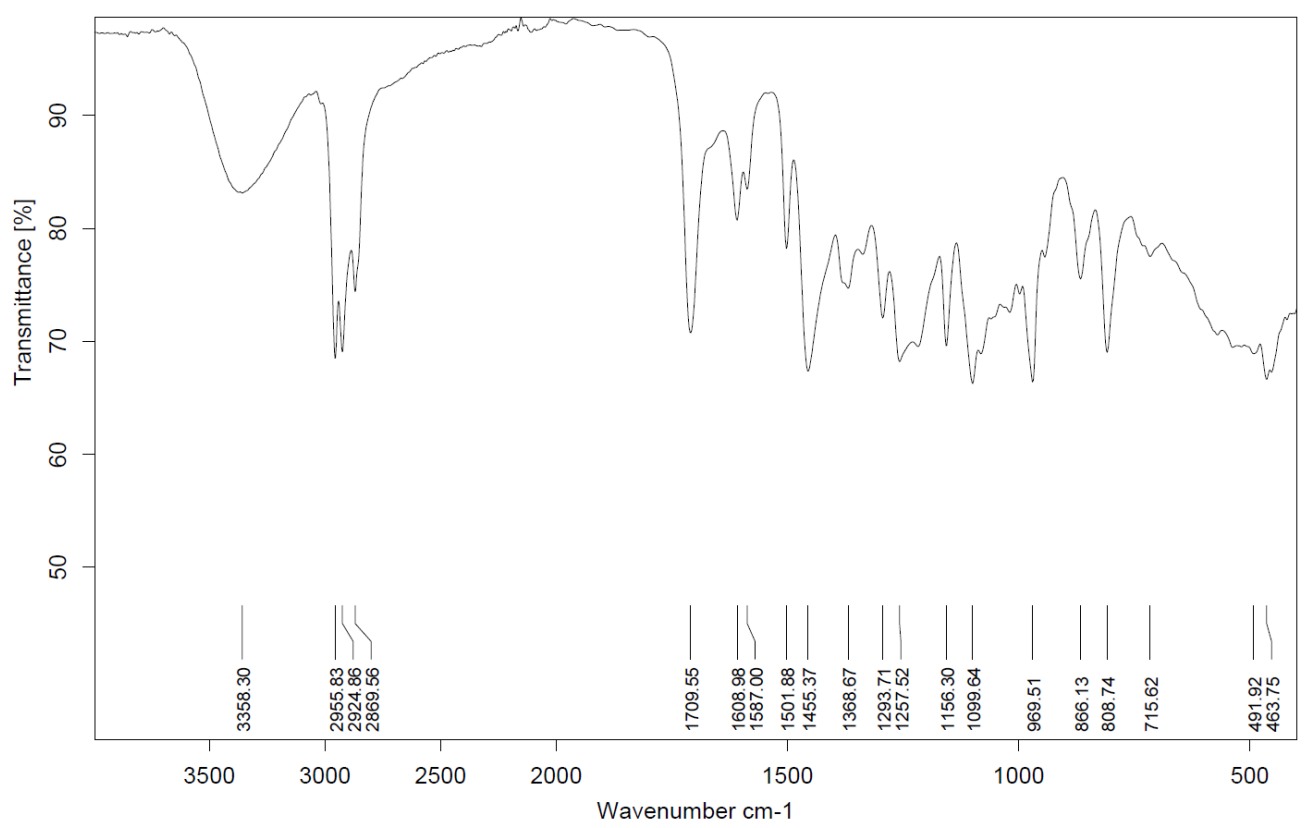

D:IDATAI-军大IF55.0 F55 Instrument type and / or accessory 01/06/2018

Page 1/1

Figure S29. IR spectrum of 4

State Key Laboratory of Organometallic Chemistry Shanghai Institute of Organic Chemistry

Chinese Academy of Sciences

光谱测定报告

打印日期时间: 2018/03/21

文件名：f55-RawData

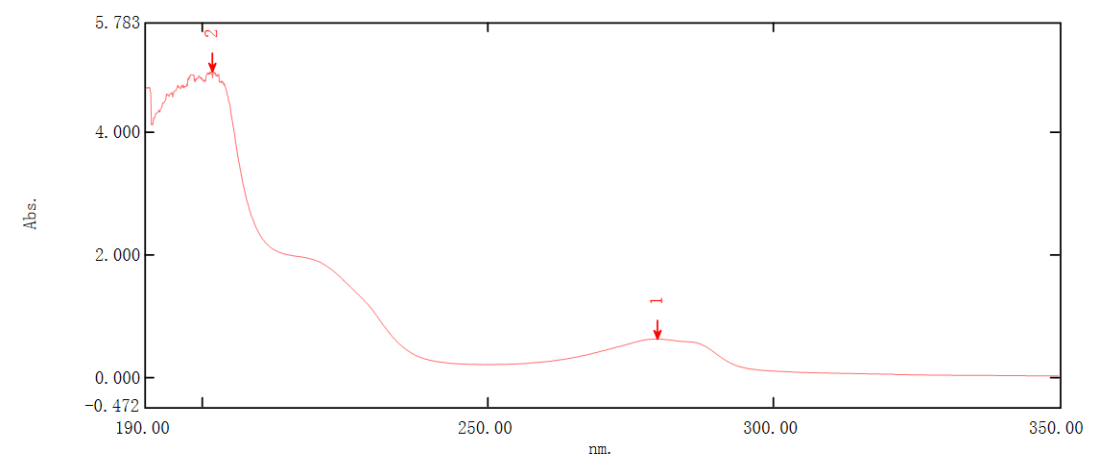

\begin{tabular}{|r|r|r|r|r|}
\hline No. & P/V & 波长(nm) & Abs. & 描述 \\
\hline 1 & ( $)$ & 279.60 & 0.626 & \\
\hline 2 & $\mathbf{\uparrow}$ & 201.90 & 4.992 & \\
\hline 3 & $\mathbf{0}$ & 250.00 & 0.209 & \\
\hline
\end{tabular}

Figure S30. UV spectrum of 4 


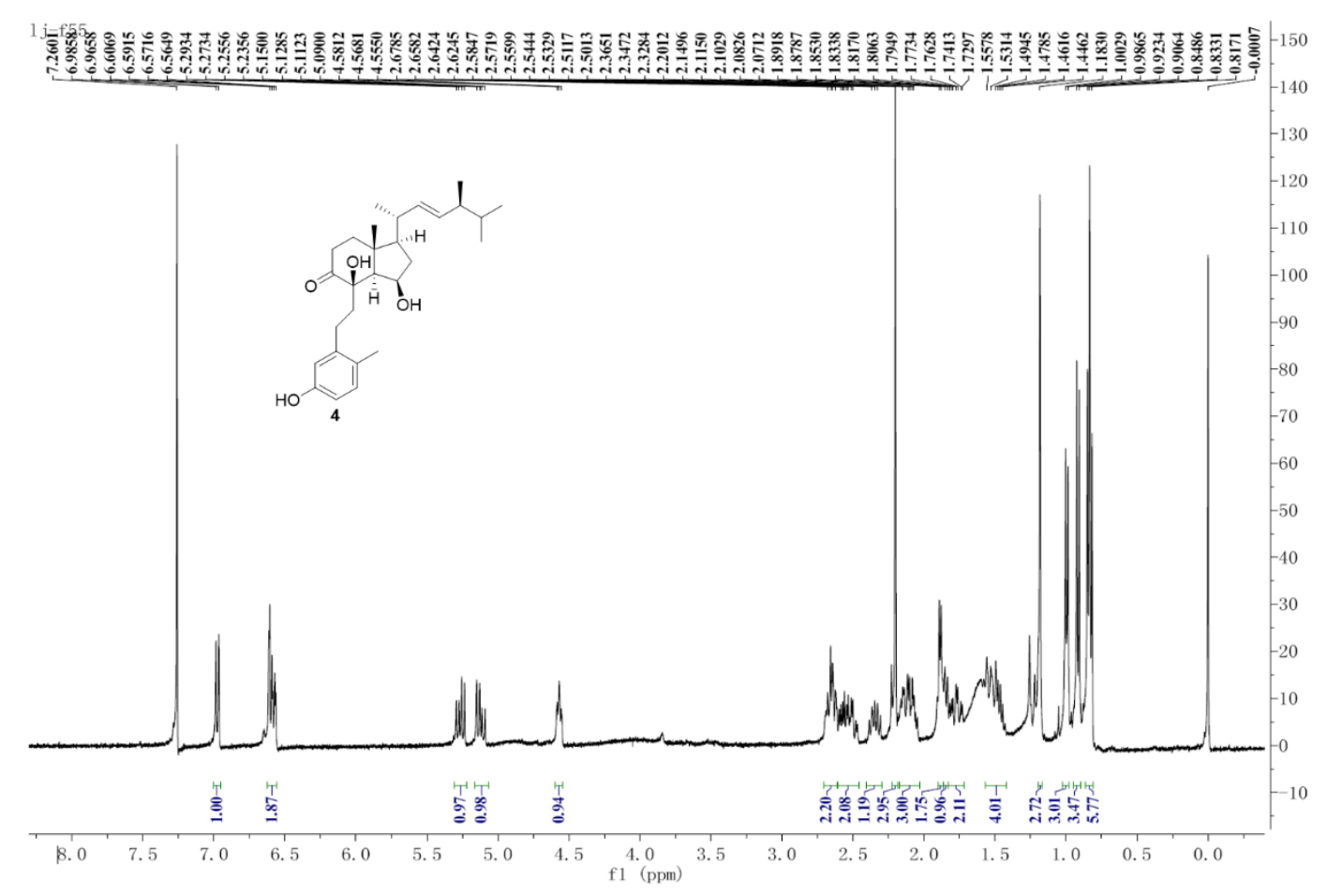

Figure S31. ${ }^{1} \mathrm{H}$ NMR $\left(600 \mathrm{MHz}, \mathrm{CDCl}_{3}\right)$ spectrum of 4

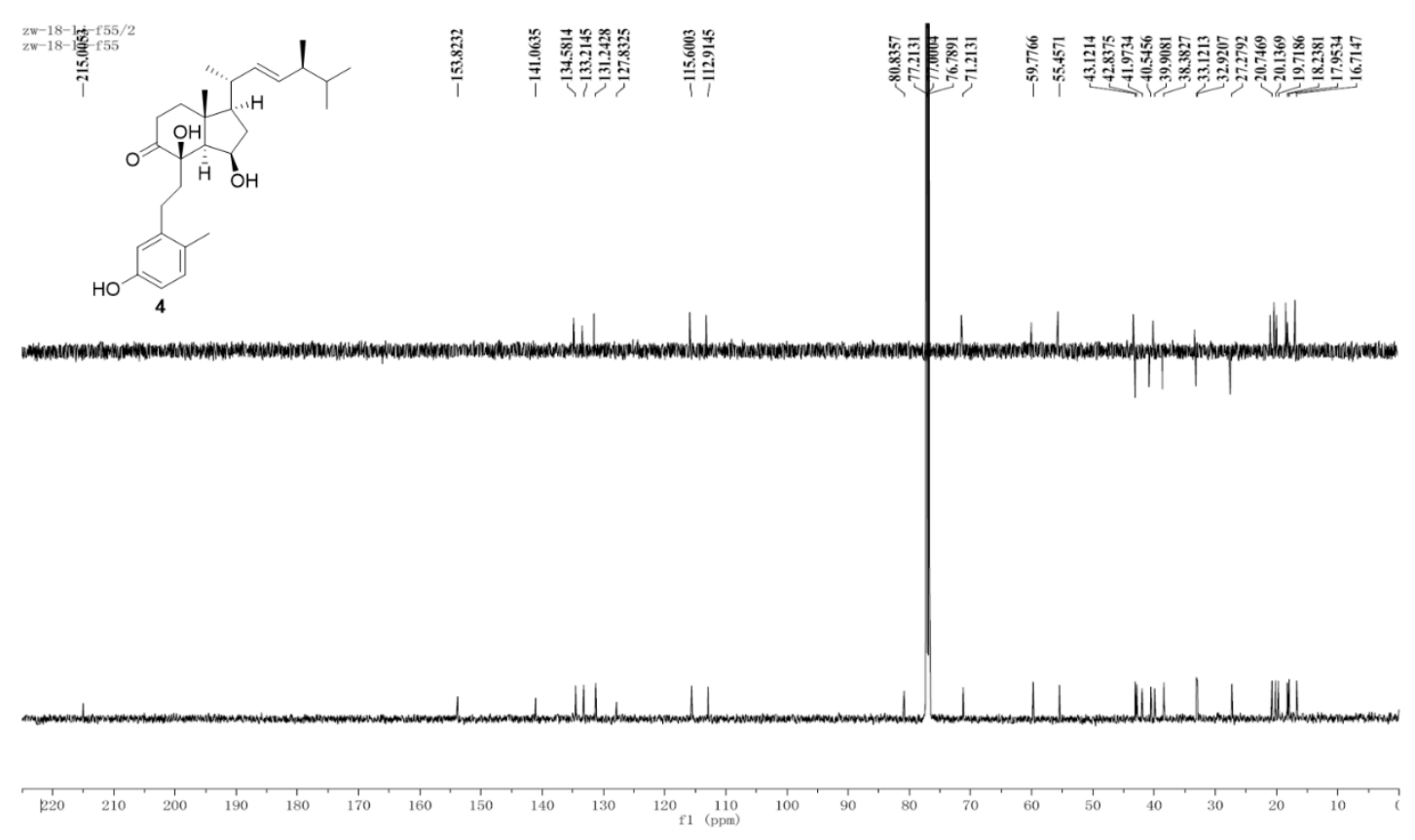

Figure S32. ${ }^{13} \mathrm{C}-\mathrm{NMR}$ and DEPT $\left(150 \mathrm{MHz}, \mathrm{CDCl}_{3}\right)$ spectrum of 4 


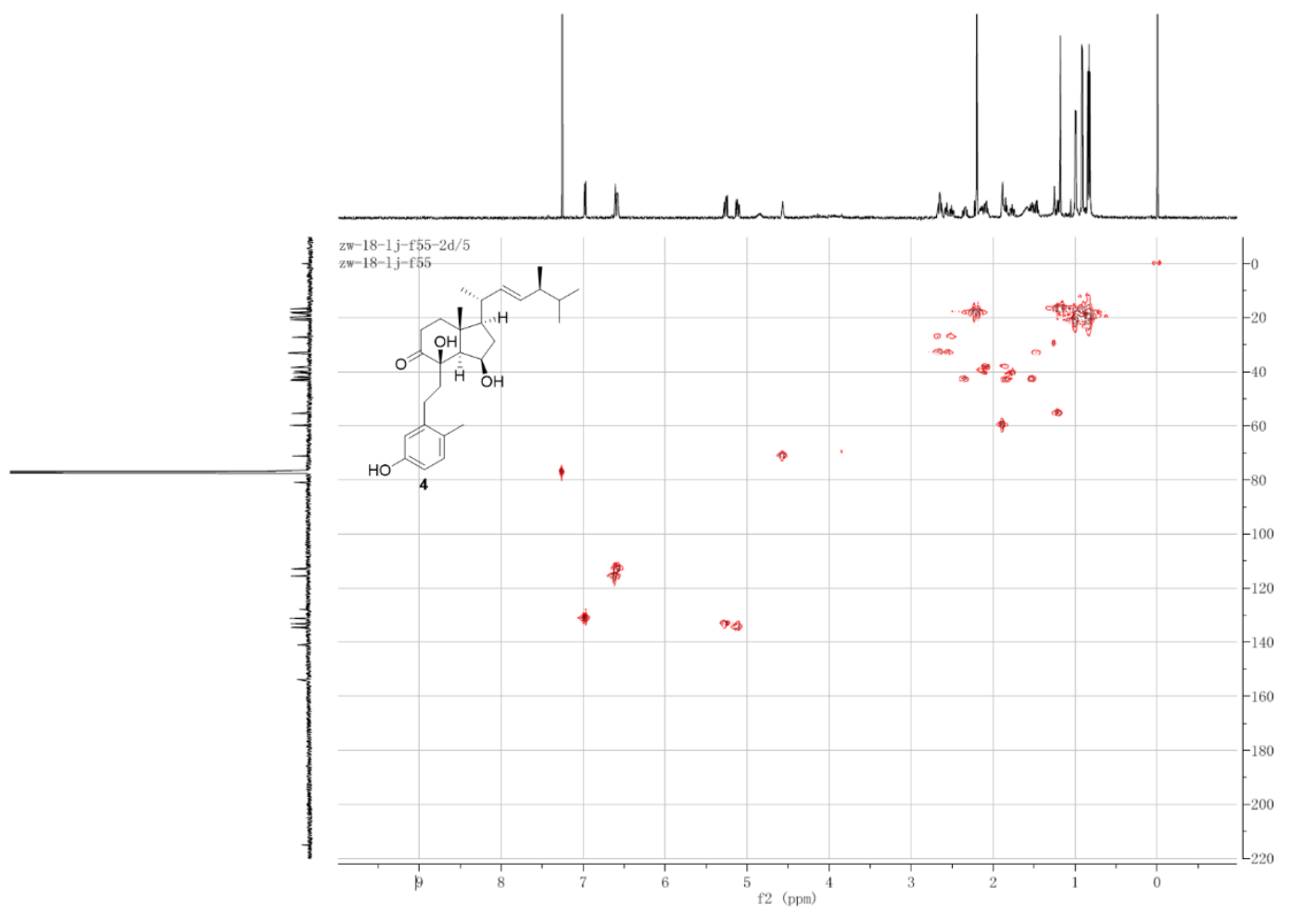

Figure S33. HSQC spectrum of 4 in $\mathrm{CDCl}_{3}$

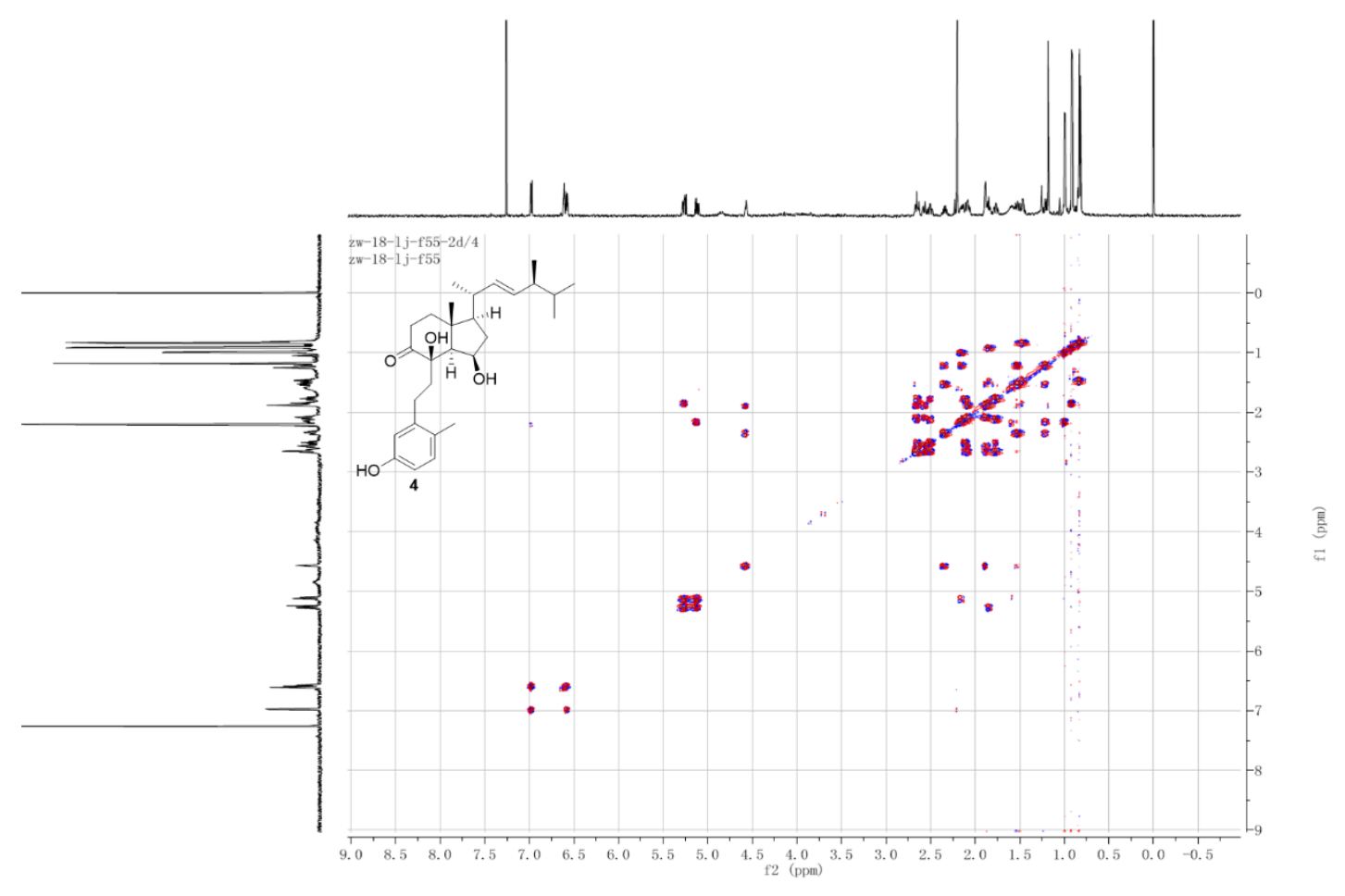

Figure S34. ${ }^{1} \mathrm{H}-{ }^{1} \mathrm{H}$ COSY spectrum of 4 in $\mathrm{CDCl}_{3}$ 


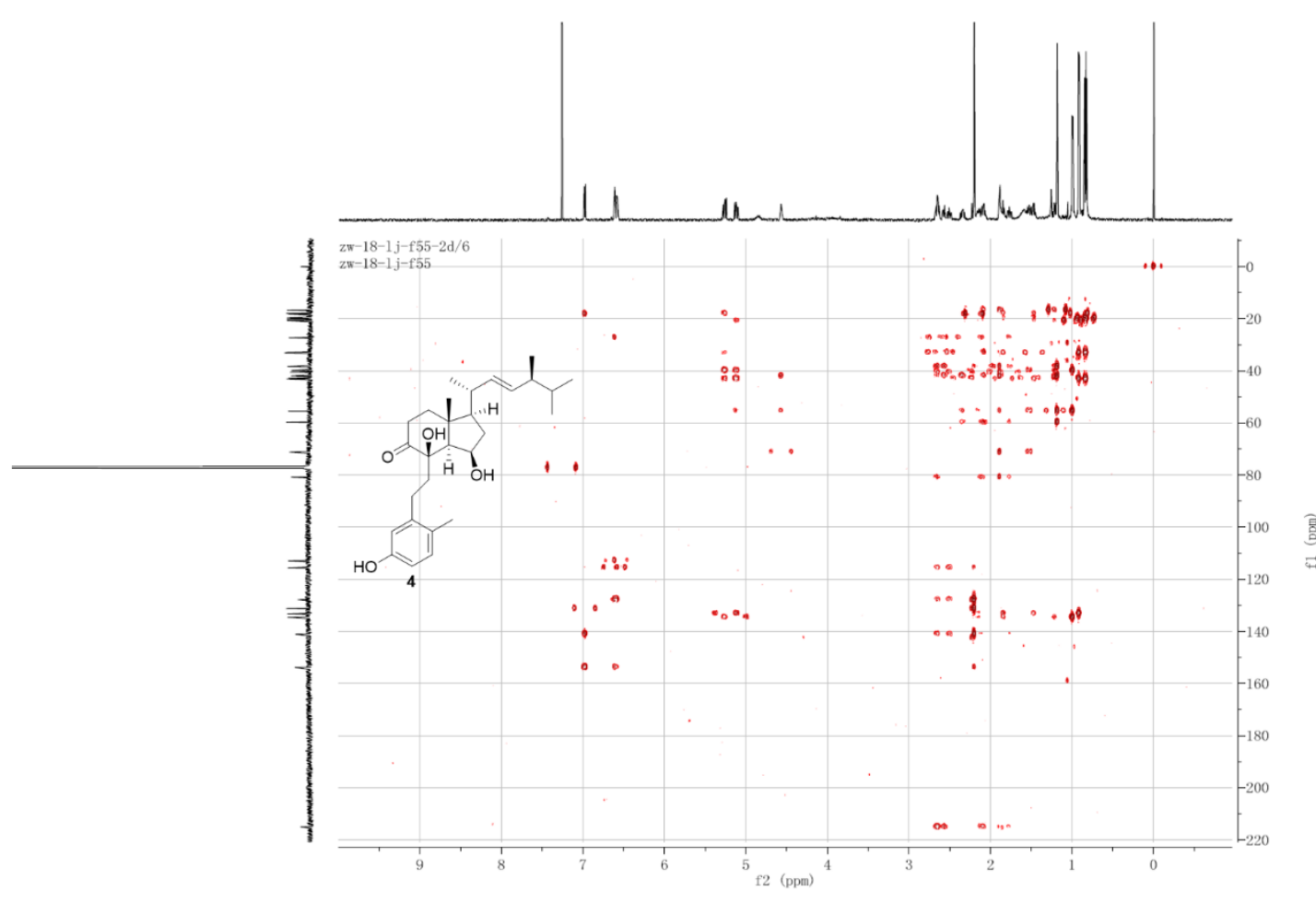

Figure S35. $\mathrm{HMBC}$ spectrum of 4 in $\mathrm{CDCl}_{3}$

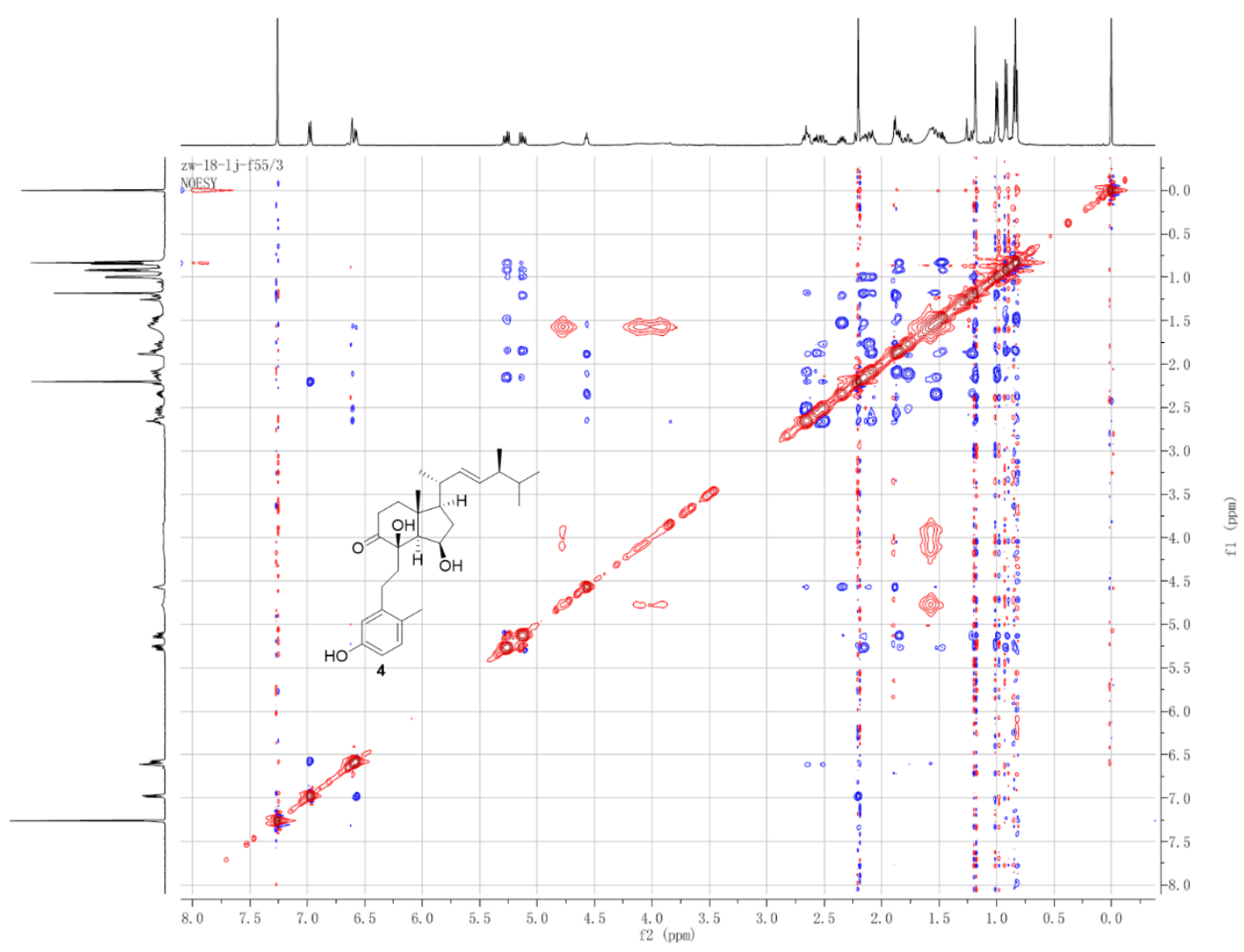

Figure S36. NOESY spectrum of 4 in $\mathrm{CDCl}_{3}$ 


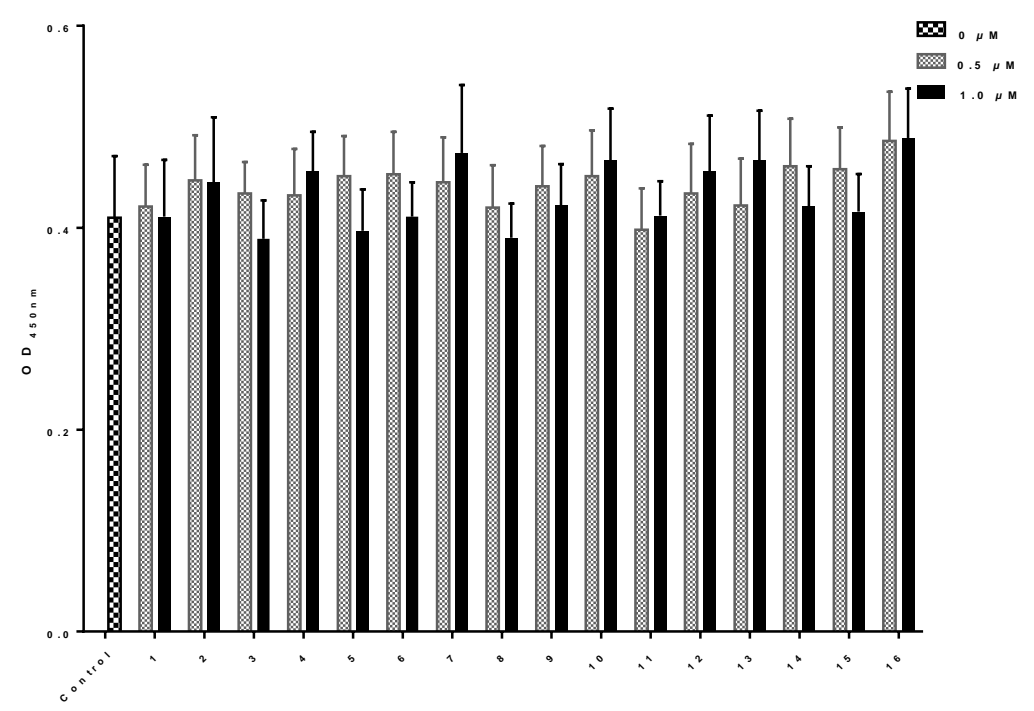

Figure S37. Compounds 1-16 showed no significant cytotoxicity on spleen mononuclear cells (SMNCs) comparing with the blank control groups at the concentrations of 0.5 and $1.0 \mu \mathrm{M}$ for $48 \mathrm{~h}(n=3)$ 